British Journal of Nutrition (2022), 127, 1898-1920

doi:10.1017/S0007114521002609

(C) The Author(s), 2021. Published by Cambridge University Press on behalf of The Nutrition Society. This is an Open Access article, distributed under the terms of the Creative Commons Attribution licence (https://creativecommons.org/licenses/by/4.0/), which permits unrestricted re-use, distribution, and reproduction in any medium, provided the original work is properly cited.

\title{
Ketogenic diets, physical activity and body composition: a review
}

\author{
Damoon Ashtary-Larky ${ }^{1}$, Reza Bagheri ${ }^{2 *}$, Hoda Bavi $^{1}$, Julien S. Baker ${ }^{3}$, Tatiana Moro ${ }^{4}$, Laura Mancin ${ }^{4,5}$ and \\ Antonio Paoli ${ }^{4,5,6}$ \\ ${ }^{1}$ Nutrition and Metabolic Diseases Research Center, Abvaz Jundishapur University of Medical Sciences, Ahvaz, Iran \\ ${ }^{2}$ Department of Exercise Physiology, University of Isfahan, Isfahan, Iran \\ ${ }^{3}$ Centre for Health and Exercise Science Research, Department of Sport, Physical Education and Health, Hong Kong Baptist \\ University, Kowloon Tong, Hong Kong \\ ${ }^{4}$ Department of Biomedical Sciences, University of Padua, Padua, Italy \\ ${ }^{5}$ Human Inspired Technology Research Center, University of Padua, Padua, Italy \\ ${ }^{6}$ Research Center for High Performance Sport, UCAM, Catholic University of Murcia, Murcia, Spain
}

(Submitted 11 December 2020 - Final revision received 5 June 2021 - Accepted 5 July 2021 - First published online 12 July 2021)

\section{Abstract}

Obesity remains a serious relevant public health concern throughout the world despite related countermeasures being well understood (i.e. mainly physical activity and an adjusted diet). Among different nutritional approaches, there is a growing interest in ketogenic diets (KD) to manipulate body mass (BM) and to enhance fat mass loss. KD reduce the daily amount of carbohydrate intake drastically. This results in increased fatty acid utilisation, leading to an increase in blood ketone bodies (acetoacetate, 3 - $\beta$-hydroxybutyrate and acetone) and therefore metabolic ketosis. For many years, nutritional intervention studies have focused on reducing dietary fat with little or conflicting positive results over the long term. Moreover, current nutritional guidelines for athletes propose carbohydrate-based diets to augment muscular adaptations. This review discusses the physiological basis of KD and their effects on BM reduction and body composition improvements in sedentary individuals combined with different types of exercise (resistance training or endurance training) in individuals with obesity and athletes. Ultimately, we discuss the strengths and the weaknesses of these nutritional interventions together with precautionary measures that should be observed in both individuals with obesity and athletic populations. A literature search from 1921 to April 2021 using Medline, Google Scholar, PubMed, Web of Science, Scopus and Sportdiscus Databases was used to identify relevant studies. In summary, based on the current evidence, KD are an efficient method to reduce BM and body fat in both individuals with obesity and athletes. However, these positive impacts are mainly because of the appetite suppressive effects of KD, which can decrease daily energy intake. Therefore, KD do not have any superior benefits to non-KD in $\mathrm{BM}$ and body fat loss in individuals with obesity and athletic populations in an isoenergetic situation. In sedentary individuals with obesity, it seems that fat-free mass (FFM) changes appear to be as great, if not greater, than decreases following a low-fat diet. In terms of lean mass, it seems that following a KD can cause FFM loss in resistance-trained individuals. In contrast, the FFM-preserving effects of KD are more efficient in endurance-trained compared with resistance-trained individuals.

Key words: Body composition: Fat-free mass: Fat mass: Resistance training: Endurance training: Obesity: Ketogenic diet

Obesity remains a significant public health concern throughout the world. According to the latest data from the WHO, the prevalence of obesity is increasing, with $13 \%$ of adults worldwide classified as obese and $39 \%$ classified as overweight ${ }^{(1)}$. Associated co-morbidities such as CVD, type 2 diabetes mellitus and various types of cancers are expected to rise dramatically in conjunction with the global obesity epidemic ${ }^{(2-4)}$. While increasing efforts continue to combat this disease, body mass (BM) loss strategies remain a complex and challenging dilemma for health care practitioners and individuals with obesity. Various dietary strategies have long been proposed for BM loss. One popular dietary strategy is classifying a diet based on macronutrient intake, including fat, protein and carbohydrate. Based on dietary carbohydrate intakes, diets can be classified as very-low-carbohydrate ketogenic diet (KD) ( $<5 \%$ carbohydrates or $<50 \mathrm{~g} / \mathrm{d})$, very-lowcarbohydrate diet (LCD) (<10\% carbohydrates), LCD $(<25 \%$

Abbreviations: AcAc, acetoacetate; AMPK, AMP-activated protein kinase; BFP, body fat percentage; BHB, 3- $\beta$-hydroxybutyrate; BM, body mass; ET, endurance training; FFM, fat-free mass; FM, fat mass; GH, growth hormone; HIIT, high-intensity interval training; IGF-1, insulin-like growth factor-1; KB, ketone body; KD, ketogenic diet; LCD, low-carbohydrate diet; LFD, low-fat diet; MPB, muscle protein breakdown; MPS, muscle protein synthesis; mTOR, mechanistic target of rapamycin; PGC1- $\alpha$, PPAR- $\gamma$ coactivator $1-\alpha$; RT, resistance training; SIRT-1, sirtuin- 1.

* Corresponding author: Reza Bagheri, email will.fivb@yahoo.com 
carbohydrates or $<130 \mathrm{~g} / \mathrm{d}$ ), moderate-carbohydrate diet (25$44 \%)$ and high-carbohydrate diet ( $45 \%$ or greater) ${ }^{(5-7)}$.

Nowadays, a low-carbohydrate approach is a popular strategy for decreasing BM and fat mass (FM). Based on the previously mentioned classifications, a KD is a very LCD, high in fat, with variation in protein intake but may be classified as moderate or high ${ }^{(8)}$. This macronutrient distribution leads to an increase in the production of ketone bodies $(\mathrm{KB})$ and consequently to physiological ketosis (i.e. blood KB concentrations between 1 and $4 \mathrm{~mm}$ and blood potential of hydrogen $(\mathrm{pH})$ of $\approx 7.4)^{(9)}$.

The literature outlines that carbohydrate-restricted diets (LCD and KD) are increasingly used to manage various health conditions, including neurological disorders, obesity, dyslipidaemia, hypertension, diabetes, the metabolic syndrome and various cancers $^{(6,10)}$. As a result, carbohydrate-restricted diets have gained substantial popularity. In the USA, The Health Information National Trends Survey of 5586 participants reported among respondents who were aware of carbohydrate-restricted diets that approximately $17 \%$ had tried LCD during the last year and one-third of respondents who were aware of LCD confirmed that they are employing a healthy strategy to control $\mathrm{BM}^{(11)}$. In the UK, media reports suggest that $7 \%$ of men and $10 \%$ of women are experimenting with carbohydrate-restricted diets ${ }^{(12)}$ and similar population values are reported from Finland ${ }^{(13)}$

KD may act as a viable strategy for BM loss, particularly in the short term; however, BM loss may be accompanied by a loss of lean mass. Due to the importance of $\mathrm{BM}$ and the relevance of properly maintaining body composition ${ }^{(14)}$, the efficacy of $\mathrm{KD}$ on BM and body composition is an intriguing area of experimental research ${ }^{(15,16)}$. A focus on body composition during BM loss is critical to monitor changes in FM while maintaining or even improving lean mass ${ }^{(17)}$. A KD-derived BM loss programme is acknowledged as an efficient intervention within the first few weeks of implementation ${ }^{(18)}$. However, it has been suggested that a significant amount of BM loss includes reductions in lean mass and FM with changes in body fluid status ${ }^{(19)}$.

Nevertheless, the evidence for body composition alterations during a KD is inconclusive. Therefore, we aim to review the current evidence regarding the impact of various KD on body composition, with a focus on changes in body fat (FM or body fat percentage (BFP)) and lean mass. We will also critique the methodologies used to evaluate changes in body composition in athletes and individuals who are overweight and obese.

\section{Literature search}

A literature search from 1921 to April 2021 using Medline, Google Scholar, PubMed, Web of Science, Scopus and Sportdiscus databases was used to identify relevant studies. The following keywords, alone or in conjunction, were used to find relevant articles: 'ketogenic diet', 'very-low-carbohydrate high-fat diet', 'very-low-carbohydrate diet', 'carbohydraterestricted diet', 'VLCD', 'body composition', 'weight', 'fat mass', 'fat-free mass', 'lean body mass', 'muscle mass', 'keto-adaptation', 'athletes', 'obesity', 'obese', 'overweight', 'resistance training', 'strength training', 'endurance training', 'aerobic training', 'high intensity interval training' and 'HIIT'. All eligible studies were in English. For this review, the inclusion criteria focused on using $\mathrm{KD}$ alone or in combination with exercise on BM loss and changes in lean mass and body fat. All studies had to provide a detailed explanation of their KD protocol. Studies included both males and females. As described in the following paragraph, a KD can vary slightly in the composition of the macronutrients and thus can be classified differently. In this review, we have considered only studies that used diets with $<50 \mathrm{~g} / \mathrm{d}$ and/or $<5 \%$ of carbohydrates and we will refer generically to a KD or very LCD throughout the manuscript.

\section{History and definition of ketogenic diet}

The KD has been studied periodically for more than 100 years $^{(20,21)}$. However, over the past 30 years, a growing body of research has suggested that a link exists between the process of KD adaptation and a broad range of health benefits ${ }^{(20)}$. Dr. Russel Wilder first used this type of diet to treat epilepsy in $1921^{(22)}$ and described the term 'ketogenic diet.' Because of Wilder's observed beneficial results, the KD assumed a place in medical nutrition as a therapeutic diet for paediatric epilepsy and was widely used until its popularity declined as antiepileptic agents were introduced ${ }^{(23,24)}$. The classic KD is a type of verylow-carbohydrate and high-fat diet that concurrently restricts energy content. Typically, carbohydrate intake is reduced to $<30 \mathrm{~g} / \mathrm{d}$; however, studies show that this number is not necessarily consistent to induce ketosis and fluctuates between 20 and $50 \mathrm{~g} / \mathrm{d}^{(9,24,25)}$

This diet serves to mimic a fasting state by shifting the utilisation of fats as a primary fuel source via the catabolism of fatty acids in the liver. KB are produced by the liver ${ }^{(26)}$. Nutritional ketosis is a clinically benign and physiological ${ }^{(27)}$ metabolic state that should not be confused with a pathological state of ketoacidosis, a hazardous complication of conditions including diabetes mellitus or alcoholism ${ }^{(28)}$. Ketosis in individuals typically leads to maximum blood $\mathrm{KB}$ concentrations of 4-5 mM, whereas concentrations in ketoacidosis often exceed ten times these values $^{(29)}$.

\section{Types of ketogenic diets}

There are several versions of the KD. However, we considered only the following types of $\mathrm{KD}$, which are more readily available in the scientific literature. In addition to the explanations, Table 1 summarises the information.

\section{Classic ketogenic diet}

Historically, classic KD was proposed by Dr. Wilder in a series of patients with epilepsy in the Mayo Clinic $^{(22)}$. The classic therapeutic $\mathrm{KD}$ (fat $=90 \%$, protein $=6 \%$, carbohydrate $=4 \%$ ), initially created to manage childhood seizures, has a $4: 1$ ratio of grams of fat:grams carbohydrate plus protein ${ }^{(30,31)}$.

\section{The modified Atkins diet}

Modified Atkins diet limits the amount of carbohydrates consumed to $10-20 \mathrm{~g} / \mathrm{d}$ (10 g for children and $20 \mathrm{~g}$ for adults), which 
Table 1. Types of ketogenic diets (KD)

\begin{tabular}{|c|c|c|c|}
\hline Type of KD & Abbreviation & $\begin{array}{l}\text { Macronutrient } \\
\text { distribution }\end{array}$ & Characteristics \\
\hline Classic ketogenic diet & Classic KD & $\begin{array}{l}\text { CHO: } 4 \% \\
\text { Fat: } 90 \% \\
\text { Pro: } 6 \%\end{array}$ & Created for the management of childhood seizures \\
\hline The Modified Atkins Diet & MAD & $\begin{array}{l}\text { CHO: } 5 \% \text { ( } 10 \mathrm{~g} \text { for children } \\
\quad \text { and } 20 \mathrm{~g} \text { for adult) } \\
\text { Fat: } 65 \% \\
\text { Pro: } 30 \%\end{array}$ & No energy restriction \\
\hline Very low-energy ketogenic diet & VLCKD & $\begin{array}{l}\text { CHO: } 13 \%(<30 \mathrm{~g} / \mathrm{d}) \\
\text { Fat: } 44 \% \\
\text { Pro: } 43 \%(1.2-1.5 \mathrm{~g} / \mathrm{kg})\end{array}$ & $\begin{array}{l}\text { Mimics fasting through a noticeable restriction of daily carbohy- } \\
\text { drate and energy }(<800 \mathrm{kcal}) \text { intake }\end{array}$ \\
\hline $\begin{array}{l}\text { Ketogenic Mediterranean diet/ } \\
\text { Modified Mediterranean } \\
\text { Ketogenic diet }\end{array}$ & KMD or MMKD & $\begin{array}{l}\text { CHO: }<30 / 50 \mathrm{~g} / \mathrm{d} \\
\text { Fat: } 45-50 \% \\
\text { Pro: } 30-35 \%\end{array}$ & $\begin{array}{l}\text { Emphasising on the intake of lean meats, fish, olive oil, walnuts } \\
\text { and green vegetables and, in some protocols, the addition of } \\
\text { herbal extracts }\end{array}$ \\
\hline
\end{tabular}

$\mathrm{CHO}$, carbohydrate.

Table 2. Frequently recommended foods in a ketogenic diet (KD)

\begin{tabular}{llllll}
\hline Animal protein & Dairy products & Fats & Nuts and seeds & Fruits & Vegetables \\
\hline Eggs & Cheese (especially full fat) & Olive oil & Almonds & Avocados & All green leafy \\
Meats & Cream Cheese & Fats & Flaxseeds & Strawberry & Carrot \\
Poultry & Cream & Coconut oil & Macadamia nuts & Lemon & Mushroom \\
Game & Butter & MCT oil/powder & Brazil nuts & Berries & Eggplant \\
Seafood & Full fat, no sugar yogurt & Avocado oil & Pecans & Olive & Tomato \\
\hline
\end{tabular}

was introduced as an alternative to the classic KD in $2003^{(32)}$. Modified Atkins diet does not restrict energy content, fluid or protein and allows a greater portion of carbohydrate and protein intake than the classic $\mathrm{KD}^{(33)}$ (e.g. fat $=65 \%$, protein $=30 \%$, carbohydrate $=5 \%)^{(32)}$.

\section{Very low-energy ketogenic diet}

Very low-energy ketogenic diet is a nutritional intervention that mimics fasting through a noticeable restriction of daily carbohydrate intake, usually lower than $30 \mathrm{~g} / \mathrm{d}(\simeq 13 \%$ of daily energy intake). The diet includes a relative increase in the proportions of fat $(\simeq 44 \%)$ and protein $(\simeq 43 \%$ or $\simeq 1 \cdot 2-1.5 \mathrm{~g} / \mathrm{kg}$ of ideal BM), and with a total energy intake of $<800 \mathrm{kcal} / \mathrm{d}$, depending on the amount and quality of protein preparations ${ }^{(34)}$.

\section{Ketogenic Mediterranean diet/Modified Mediterranean Ketogenic diet}

The Mediterranean version of the KD has been widely studied in previous years. Basically, it is a very LCD (carbohydrate lower than $30 / 50 \mathrm{~g} / \mathrm{d}$ ) in which emphasis is placed on the intake of lean meats, fish, olive oil, walnuts and salad ${ }^{(35-40)}$ and, in some protocols, the addition of herbal extracts ${ }^{(41-45)}$.

\section{Food selections in ketogenic diet}

Food selection is a major consideration for individuals undergoing a KD. High-carbohydrate food consumption is strictly controlled and limited during a $\mathrm{KD}^{(46)}$; however, it is not a "no carbohydrate diet.' Meal preparation often incorporates unprocessed foods consisting primarily of cruciferous and leafy green vegetables, raw nuts and seeds, eggs, fish, unprocessed animal meats, high-fat dairy products and natural plant oils, including fats, avocados, coconuts and olives ${ }^{(47-49)}$. In addition to the KD foods listed in Table 2, ketogenic eating plans frequently promote meals such as omelettes, salads and animal protein such as steak, salmon or chicken with vegetables ${ }^{(50,51)}$. In addition, some proprietary/commercial meals are used that mimic the taste of carbohydrates but are very low in carbohydrates ${ }^{(52,53)}$.

\section{Mechanism of ketogenesis}

Glucose is a vital fuel substrate for fat oxidation and central nervous system activity. Its role is particularly crucial in cell energy production because it is a precursor of oxaloacetate, a required substrate for the Krebs cycle ${ }^{(54)}$. The Krebs cycle also gives its intermediates in other biosynthetic processes. This intermediate pool replenishment process is called anaplerosis ${ }^{(55)}$. The endogenous production of glucose in the body, particularly in the liver, from lactate, glycerol and the amino acids alanine and glutamine is known as gluconeogenesis. When gluconeogenesis fails to keep pace with bodily needs for glucose, ketogenesis begins in earnest to provide an alternate source of energy ${ }^{(56,57)}$.

In humans and most other mammals, acetyl-CoA formed in the liver during the oxidation of fatty acids can either enter the Krebs cycle or undergo conversion to $\mathrm{KB}^{(58)}$. During a $\mathrm{KD}$, the concentrations of glucose drop and the glucose reserve is not enough to guarantee oxaloacetate production for anaplerotic function. In this condition, the organism requires an alternative source of energy, which is found in the form of $\mathrm{KB}^{(23,56,59)}$. The three $\mathrm{KB}$ are acetoacetate (AcAc), beta-hydroxybutyrate (BHB) and acetone ${ }^{(60)}$. The production of $\mathrm{KB}$ occurs in the liver from 
two acetyl-CoA molecules through a metabolic process called ketogenesis $^{(61)}$. When oxaloacetate is not available due to a shortage of glucose, acetyl-CoA accumulates and spontaneously diverts into the formation of $\mathrm{AcAc}$, and then $\mathrm{BHB}^{(56)}$. Two molecules of acetyl-CoA catalysed by thiolase and produce acetoacetyl-CoA ${ }^{(62-64)}$. The acetoacetyl-CoA then condenses with acetyl-CoA to form beta-hydroxy-beta-methylglutarylCoA cleaved to free AcAc and acetyl-CoA. The AcAc is reversibly reduced by $\mathrm{BHB}$ dehydrogenase, a mitochondrial enzyme, to BHB. AcAc can also form acetone. In healthy people, acetone is formed in very small amounts either from AcAc, which is easily decarboxylated spontaneously or by the action of AcAc decarboxylase.

$\mathrm{KB}$ are then released into the bloodstream and can be absorbed by other tissues to be reconverted to acetyl-CoA and therefore provide a fuel substrate for the Krebs cycle ${ }^{(65)}$. This process is of importance for the brain due to its incapability to utilise directly NEFA as a source of energy. NEFA are unable to cross the blood-brain barrier. For this reason, the brain ordinarily uses glucose and, in low glucose conditions, becomes dependent upon $\mathrm{KB}^{(61)}$. The rapid rise of circulating $\mathrm{KB}$ leads to ketonaemia and ketonuria. Excretion of acetone, the volatile $\mathrm{KB}$, through the lungs causes the characteristic sickly-sweet odour of ketosis $^{(66)}$.

\section{Nutritional ketosis and mechanisms of ketogenic diet}

Previously, interest in the KD focused on its role in epilepsy and expanded upon our knowledge of underlying biochemical mechanisms in both normal and pathologic brain function ${ }^{(67,68)}$. The KD acts by inducing a state of physiological ketosis, which has been linked metabolically to some anticonvulsant properties via reduced glucose, elevated fatty acid concentrations and enhanced bioenergetics reserves ${ }^{(69)}$. Besides, regarding its effects on brain function and anticonvulsant effects, KD affect numerous other physiological and biochemical processes. Dramatically reducing carbohydrate intake and thus decrements of insulin and leptin and increased glucagon concentrations also play a role in regulating protein and TAG balance, which results in reduced lipogenesis while increasing lipolysis ${ }^{(70,71)}$. Interestingly, fuel sources in a $\mathrm{KD}$ are fatty acids $(70 \%$ of energetic requirements from dietary fat and lipolysis of adipose tissue pools), KB (20\% of energetic requirements from lipolysis and ketogenesis adipose stores) and glucose (10\% of energy requirements from gluconeogenesis ${ }^{(72)}$. Numerous factors such as BMR, BMI and BFP may be improved through ketogenesis ${ }^{(23,73)}$. Ketosis induced by nutritional strategy preserves concentrations of $\mathrm{KB}$ at a physiological status without varying the blood $\mathrm{pH}$ and, consequently, is considered relatively safe ${ }^{(74-76)}$. The body begins using primarily ketones as energy fuel after a few days or weeks from the beginning of the diet. This phenomenon is called 'keto-adaptation' and can vary between individuals. The mechanisms that promote keto-adaptation are still poorly understood; however, some authors have proposed the hypothesis that mitochondrial biogenesis and decrements of mitochondrial damage in oxidative tissues (such as brain and muscle) may be one of the possible mechanisms ${ }^{(77,78)}$.
For example, studies on muscle tissue showed that a KD could contribute to mitochondrial biogenesis and reduce mitochondrial autophagy, contributing to a rich mitochondrial reservoir in the muscle tissue, enhancing exercise performance and athletic' well-being ${ }^{(79,80)}$. Others believe that $\mathrm{KB}$ can reduce histone deacetylation, which acts as active signalling molecules and promotes important epigenetic modifications ${ }^{(76,81)}$.

\section{Side effects of ketogenic diets}

KD' serious complications appear to be rare; however, preexisting conditions such as porphyria, pyruvate carboxylase deficiency, defects in fatty acids oxidation and mitochondrial disorders have reportedly worsened over time ${ }^{(82)}$. Adverse events encountered during KD can be categorised into short-term and long-term side effects.

Dehydration is typically characterised by dry mouth, headache, dizziness/orthostatic hypotension and electrolyte abnormalities (such as hyponatraemia and hypomagnesaemia), and visual disturbance is the most common short-term side effect ${ }^{(83)}$. Furthermore, hypoglycaemia (due to carbohydrate restriction), lethargy (due to switching from utilising carbohydrates to fat for ATP production), halitosis (caused by ketosis and increasing in acetone concentrations), gastrointestinal disturbances, involving nausea/vomiting, diarrhoea or constipation (due to gastrointestinal response to high fat intake), and hyperuricaemia are other short-term side effects of $\mathrm{KD}^{(83-85)}$.

Long-term side effects of $\mathrm{KD}$ include hypoproteinaemia (as a consequence of gluconeogenesis following carbohydrate restriction especially accomplished with low protein intake), hypocalcaemia and bone damage (probably due to low $\mathrm{Ca}$ intake), increasing LDL, urolithiasis (represented by chronic acidosis, dehydration and fat malabsorption), gallstones (due to rapid BM loss) and hair loss (especially when protein intake is insufficient) ${ }^{(83)}$.

\section{Effects of ketogenic diet on body mass and fat mass loss}

During recent years, KD have been commonly considered a beneficial strategy to treat numerous diseases and BM and FM control. In fact, many studies suggest that they could be more efficient than low-fat diets (LFD) ${ }^{(86-89)}$. The efficacy of KD on $\mathrm{BM}$ and $\mathrm{FM}$ loss is related to predisposing factors, and its possible mechanisms are mainly a reduction of energy intake and appetite and an increase in daily energy expenditure.

Regarding predisposing factors, numerous findings have shown that baseline insulin dynamics or genotype patterns could play an important role in the success of a LFD $v$. a KD on BM loss ${ }^{(90-94)}$. For instance, individuals with greater insulin resistance might be more successful following KD due to the reduced requirement on insulin to clear a lower quantity of dietary carbohydrates delivered in the blood circulation ${ }^{(90)}$. Rock et al. showed that insulin-sensitive women lost more BM at 12 months in the LFD than the LCD group ${ }^{(95)}$. However, some studies did not reveal differential effects following the low fat $v$. LCD on BM loss by baseline insulin status ${ }^{(96,97)}$. Moreover, some 
studies have reported that genotype variation could predispose individuals to differentially respond to BM loss influenced by diet type ${ }^{(98,99)}$. In the first retrospective study, a 3-fold difference was observed following 12-month BM loss for initially overweight women who were determined to have been appropriately matched (mean BM loss of $6 \mathrm{~kg}$ ) $v$. mismatched (mean BM loss of $2 \mathrm{~kg}$ ) to a low-fat or LCD based on multilocus genotype patterns with SNP from three genes (PPAR Gamma, Adrenoceptor Beta 2 and Fatty Acid Binding Protein 2) relevant to fat and carbohydrate metabolism (a putative low-fat-responsive genotype and a low carbohydrate-responsive genotype, respectively). The participants with the low-fat-responsive genotype were observed to lose more BM when assigned to an LFD than those assigned to an LCD, and vice versa for those with the lowcarbohydrate-responsive genotype ${ }^{(99,100)}$.

Adipose tissue is the main target of a BM loss programme. KD are based on the premise that reducing carbohydrate intake results in increased fat oxidation. Average interstitial glycerol concentrations (index of lipolysis) were higher following a short-term high-fat diet than an LFD based on the US Department of Agriculture food guide pyramid ${ }^{(101)}$. Reducing dietary fat intake in LFD can be an effective method to reduce energy intake and promote BM and FM loss compared with carbohydrate, protein and mixed meals ${ }^{(102)}$. In addition, in non-KD, fat intake does not immediately increase fat oxidation ${ }^{(103)}$. The amount of fatty acids that avoids capitation by adipose tissue appears to be small. It is insufficient to compensate for the decrease in NEFA release through insulin secretion in response to carbohydrates, usually consumed, and fats ${ }^{(104)}$. Conversely, KD reduce insulin concentrations, and this reduction promotes lipolysis, fat oxidation and increases energy expenditure ${ }^{(105,106)}$. However, the metabolic advantage and hyperinsulinaemic effects of the KD (the carbohydrate-insulin model of obesity) that claims diets rich in carbohydrates are particularly fattening due to their propensity to elevate insulin secretion, which was not evidenced in previous studies $^{(107,108)}$. Although it is well-established that KD can be effective in FM loss, it seems that long-term ( $>6$ months) periods may not be more effective than a well-balanced, energy-restricted $\operatorname{diet}^{(109-112)}$

Previous studies have suggested that on an energy-for-energy basis, proteins are more satiating than either carbohydrates or fats ${ }^{(113,114)}$, and it can be suggested that the higher protein intake in KD plays a critical role in limiting food intake ${ }^{(115)}$. Alternatively, Westerterp-Plantenga et al. showed higher satiety scores with high-protein and high-carbohydrate diets (protein/ carbohydrate/fat: 29/61/10) even over a 24-h period when compared with a high-fat diet (protein/carbohydrate/fat: 9/30/61), accrediting to fat content, the greater sense of hunger after a meal ${ }^{(116)}$. A well-designed randomised crossover study has shown that high-protein, low-carbohydrate KD reduce hunger and lower food intake significantly more than high-protein, medium-carbohydrate non-KD ${ }^{(117)}$, suggesting that reduced carbohydrate intake resulted in a decrease of energy intake of $0.7 \mathrm{MJ} / \mathrm{d}(294 \mathrm{kcal} / \mathrm{d})$ and a corresponding effect on negative energy balance. However, another study in which carbohydrate percentage was kept at $50 \%$, while the protein was modified from $15 \%$ to $30 \%$, demonstrated that greater protein intake could positively affect satiety, probably through a mechanism linked to leptin sensitivity in central nervous system ${ }^{(118)}$.

The concentrations of several hormones and nutrients influence appetite and are altered after BM loss induced by a $\mathrm{KD}^{(119,120)}$. Human studies have found that a higher insulinaemic response to meals may increase food intake ${ }^{(121-123)}$. Some studies showed that a strict LCD reduced appetite by decreasing insulin concentrations ${ }^{(16,124,125)}$. Moreover, other studies have shown a decrease in leptin and increased ghrelin concentrations, which are two hormones that regulate satiety; however, these effects were mitigated when BM-reduced participants were ketotic $^{(119,124)}$. The Liver-derived fibroblast growth factor 21 is an endocrine regulator of the ketotic state and maybe another possible mechanism for appetite suppression following $\mathrm{KD}^{(126)}$.

Regarding animal studies, it has been previously revealed that hepatic expression and liver-derived fibroblast growth factor 21 concentrations are induced through both $\mathrm{KD}$ and fasting states and are quickly suppressed by refeeding ${ }^{(126)}$. Liver-derived fibroblast growth factor 21 also induces gluconeogenesis, fatty acid oxidation and ketogenesis, a metabolic profile characteristic of fasting ${ }^{(127)}$. It has also been suggested that the anorexic effects of protein may contribute to the BM loss produced by LCD ${ }^{(128)}$.

Furthermore, it has been proposed that limited food choices may be another cause of decreasing energy intake in KD's followers $^{(129,130)}$. A meta-analysis study showed a lower hunger and desire for energy intake in individuals adhering to $\mathrm{KD}^{(131)}$. In addition, a large number of ad libitum eating studies showed that KD resulted in lower energy intake ${ }^{(86,89)}$. However, no significant differences were noted between KD and very-lowenergy diets in appetite suppression ${ }^{(131,132)}$. It seems that increased dietary fat oxidation and an increase in the concentration of BHB (i.e. ketosis) may contribute to the increased appetite suppression on a high-protein, LCD, and high-fat diet ${ }^{(132)}$. As suggested in a recent meta-analysis, it is challenging to define a 'threshold' of circulating ketone for appetite suppression ${ }^{(131)}$. However, studies have shown that BHB concentrations of $0.5 \mathrm{~mm}$ or even lower may be a potential threshold for appetite control, while higher concentrations (and accordingly more severe dietary carbohydrate restriction) may not be necessary to prevent an increase in appetite in response to energy restriction $^{(133,134)}$.

It has been hypothesised that KD may reduce BM and FM by increasing daily energy expenditure ${ }^{(16)}$. The higher thermic effects of high-protein diets such as KD can cause increases in total daily energy expenditure ${ }^{(135-137)}$. Nevertheless, it has been formerly indicated that high-fat diets would generate a more metabolically effective state than glucose, and carbohydrates might produce more post-prandial thermogenesis than fats ${ }^{(138)}$. Indeed, per energy, carbohydrates produce about 3-fold higher thermogenesis than fats (approximately 5-10\% for carbohydrates $v .3 \%$ for fat ${ }^{(139)}$, while proteins have greater thermogenic effects (approximately 20-30\%). Therefore, due to significant protein intake, KD could be considered an 'expensive' diet and consequently increased BM loss compared with other 'less-expensive diets ${ }^{(140-142)}$

On the other hand, some authors encourage the hypothesis of a different metabolic benefit of KD on BM loss ${ }^{(140)}$. Glycogen 
store depletion may encourage the body to switch the use of the particular energy-producing process such as gluconeogenesis and ketogenesis ${ }^{(15,143)}$. The required energy for gluconeogenesis has been estimated at about $400-600 \mathrm{kcal} / \mathrm{d}^{(137,141)}$. Compared with an isoenergetic high-carbohydrate diet, the metabolic advantage is estimated to be approximately 200 to 300 more energy content burned ${ }^{(71,144)}$. Reduction in the resting RQ and, therefore, a greater percentage of fats consumed for given total energy expenditure may represent another possible mechanism of KD's BM loss efficacy. It has been suggested that one of the main BM loss mechanisms of the KD might be attributed to an improvement in resting nutrient oxidation, and interestingly, this effect was long-lasting for at least $20 \mathrm{~d}$ following cessation of the $\mathrm{KD}^{(145)}$. Consistent with the metabolic advantages of carbohydrate-restricted diets, Ebbeling et al. showed a linear trend of $52 \mathrm{kcal} / \mathrm{d}$ for every $10 \%$ decrease in the contribution of carbohydrate to total energy intake ${ }^{(71)}$. Compared with high-carbohydrate diets, the authors reported that the change in total energy expenditure was $91 \mathrm{kcal} / \mathrm{d}$ greater in the moderate-carbohydrate diet and $209 \mathrm{kcal} / \mathrm{d}$ greater following LCD. In this study, the carbohydrate intake was 60,40 and $20 \%$ of daily energy in high, moderate and LCD, protein fixed at $20 \%$ of daily energy intake, and fat were 20, 40 and $60 \%$, respectively. Although Ebbeling et al. showed metabolic advantages of carbohydrate-restricted strategies, they did not determine total energy expenditure changes following very low-carbohydrate KD. However, Hall et al. did not support a large metabolic advantage following a $\mathrm{KD}^{(146)}$. In this study, authors investigated changes in energy expenditure, RQ and body composition in participants consuming a high-carbohydrate baseline diet for 4 weeks, followed by 4 weeks of an isoenergetic KD with clamped protein. The results showed that large isoenergetic changes in the proportion of dietary carbohydrates to fat transiently increase energy expenditure by only about $100 \mathrm{kcal} / \mathrm{d}$ after adjusting for BM and composition. The authors also mentioned that the BM and composition adjustments likely overestimated the energy expenditure changes during the KD because much of the BM loss was likely attributed to fluid loss rather than loss of metabolically active tissues (adipose tissue etc.). Another study by Hall et al. showed a trend for a greater degree of negative energy balance during a fat-reducing diet compared with an isoenergetic carbohydratereducing diet, but this was not statistically significant ${ }^{(147)}$. These data from different studies suggest that if there are any metabolic advantages following $\mathrm{KD}$, they could be quite small. Future studies are needed to investigate the energy expenditure changes following KD and non-KD such as LFD.

Mammals have evolved to utilise carbohydrates as their primary source of metabolic fuel, extracting energy through a series of intricate biochemical pathways ${ }^{(148)}$. The KD mimics the metabolic state of starvation, forcing the body to utilise fat as its primary source of energy ${ }^{(149)}$. Many studies have shown that this kind of nutritional approach has a solid physiological and biochemical basis, inducing effective FM $\operatorname{loss}^{(117,137,145,150,151)}$. It has been mentioned that there is an increase in lipolysis (due to reduced insulin concentrations) and promotion of BM loss by assessment of body composition in those following a $\mathrm{KD}^{(152)}$. The higher amount of lipolysis may have resulted in a higher rate of FM loss following a KD.
Many studies have shown that carbohydrate-restricted diets promote greater BM loss than conventional energy-restricted $\operatorname{LFD}^{(89,109,130,153,154)}$. However, a 36-month follow-up by Cardillo et al. showed that mean BM changes between baseline and 36 months were not different between the low-carbohydrate/high-protein and the LFD/high-carbohydrate diet group $^{(155)}$. In non-KD conditions, it seems that individuals with obesity showed no significant differences between LFD and high-fat diets during BM loss ${ }^{(10,156)}$. In addition, a meta-regression of eighty-seven studies showed that LCD were associated with a greater BM loss compared with high-carbohydrate diets, which was independent of energy intake ${ }^{(157)}$. It seems that the BM loss observed in such diets follows a biphasic pattern due to metabolic alterations, while later BM loss is more than likely attributable to restrictive food choices. It certainly seems that initial BM loss can be attributed to diuresis; KB excretion (ketonuria) increases renal $\mathrm{Na}$ and hence urinary water $\operatorname{loss}^{(146,158)}$. In addition, glycogenolysis, a prominent feature of the early stage of a $\mathrm{KD}$, is associated with concomitant water release (for every 1 $\mathrm{g}$ of glycogen stored, approximately $3 \mathrm{~g}$ of water is stored) ${ }^{(159-161)}$.

Based on previously mentioned potential mechanisms, it seems that initial BM loss can be attributed to dieresis. KB excretion (ketonuria) increases renal $\mathrm{Na}$; hence, urinary water loss and the long-term benefits of adhering to a KD on BM loss are decreased energy intake and appetite suppression. Moreover, based on the data derived from isoenergetic studies, there are no significant metabolic advantages in following KD in increasing energy expenditure. However, some short-term isoenergetic studies reported a higher $\mathrm{BM}$ loss following a $\mathrm{KD}$ than LFD $^{(162-164)}$, mainly because of diet-induced diuresis. The findings from isoenergetic studies underlined the the calorie in, calorie out' hypothesis, which stated that BM loss is not primarily determined by varying proportions of carbohydrate and fat in the diet but by the number of energy content ingested ${ }^{(165,166)}$.

Similar to BM loss, there is a body of evidence suggesting greater FM loss by adhering to a KD instead of an LFD. In addition, the findings of a well-designed randomised controlled trial found preferential FM loss in the trunk region with a KD, which was approximately 3 -fold greater than an LFD $^{(167)}$, which may have important implications for CVD treatment. Moreover, there is some evidence behind the FM-reducing effects of a $\mathrm{KD}$. In general, using fat as the primary fuel source often results in greater benefits for FM loss and improved body composition ${ }^{(168)}$. Furthermore, KD suppress appetite and have some metabolic advantages, as previously discussed. In adults, ketones are primarily derived from long-chain fatty acids stored in adipose tissue $^{(169)}$ controlled by insulin ${ }^{(170)}$. When blood glucose and insulin decrease, stimulating lipolysis allows plasma-NEFA to increase $^{(171)}$. The increase in plasma-NEFA helps meet the need for an alternative fuel to glucose for most tissues, except the brain's notable exception ${ }^{(172)}$. The increased supply of NEFA entering the liver leads to ketogenesis by condensation of two acetyl-CoA, which are present in excess due to fatty acid betaoxidation $^{(173)}$.

In conclusion, a KD could be beneficial in BM loss. The antiobesity effects of KD are mainly through lowered energy intake. Moreover, controlling appetite (induced by nutritional ketosis 
and higher daily protein intake), restrictive food choices, increasing energy expenditure, higher lipolysis and diuresis are other possible mechanisms that help BM loss in individuals adhering to a KD. In regard to body fat, KD may be a practical dietary approach for FM loss. Short-term studies demonstrate a strong FM loss effect on KD compared with non-KD ${ }^{(174,175)}$. However, although long-term studies reported that adhering to a $\mathrm{KD}$ achieves a greater BM loss compared with those adhering to an $\operatorname{LFD}^{(176,177)}$, the data relating to the long-term effects of $\mathrm{KD}$ on FM are limited ${ }^{(178)}$. Most long-term studies determined the KD' effects on body fat compared with very-low-energy KD with low-energy diets ${ }^{(179,180)}$. Obviously, in these studies, patients with obesity who followed very low-energy KD experienced lower body fat loss. Since very-low-energy KD consumed significantly lower amounts of energy content in these studies, the lower body fat loss in the very-low-energy KD group is related to more energy restriction, but not the benefit of $\mathrm{KD}$. Alternatively, in the most long-term studies, which evaluated the long-term effects of LCD, the carbohydrate intake was higher than $50 \mathrm{~g} / \mathrm{d}$ and/or $5 \%$ of daily energy intake $(86-88,181-185)$. Therefore, it is impossible to generalise these findings to KD. However, in long-term studies that make a comparison between a KD and a LFD, Foster et al. did not see any benefit of following a KD after 2 years of intervention ${ }^{(178)}$. In other studies by Brinkworth under planned isoenergetic conditions, both dietary patterns (very-low-carbohydrate, high-saturated-fat KD and a high-carbohydrate, LFD) resulted in similar fat loss after 1 year of intervention ${ }^{(112,186)}$. Therefore, in an isoenergetic condition, there is no advantage in FM loss in individuals adhering to a KD compared with a LFD. Based on the available evidence regarding FM loss, although ad libitum short-term studies reported significantly higher body fat loss following a $\mathrm{KD}$, there is not enough evidence about additional benefits of a KD compared with a LFD in long-term studies and isoenergetic conditions. However, further studies are needed to show the longterm effects of KD compared with an LFD on body fat.

\section{Effect of ketogenic diet on muscle mass}

The main concern surrounding KD is the potential loss of muscle mass. Regarding this topic, it is worth distinguishing between fatfree mass (FFM), the portion of the body composed of muscles, bones, ligaments, tendons, internal organs, essential fat and lean mass essential fat is not included. We will refer to FFM or lean mass accurately reporting terminology in the cited study for this review.

Theoretically, some different mechanisms were claimed in which KD may preserve muscle mass following BM loss. First, it is hypothesised that elevated $\mathrm{BHB}$ concentrations may have played a minor role in preventing muscle mass catabolism by reducing ${ }^{(187-189)}$. KB appear to depress muscle protein breakdown $(\mathrm{MPB})^{(188,190)}$. Previous findings have revealed that ketones, such as AcAc and its precursor BHB, may be a relevant metabolic fuel in the context of physical activity, improving athletic performance ${ }^{(191)}$, myocardial ATP generation ${ }^{(192)}$ and protective effects on muscle tissue ${ }^{(193)}$. Second, low blood glucose after adhering to a $\mathrm{KD}$ may be a potent stimulus to growth hormone $(\mathrm{GH})$ secretion $^{(194)}$. GH has a pivotal role in regulating in vivo protein metabolism ${ }^{(195,196)}$. GH enhances protein anabolism at the whole-body level, mainly by stimulating muscle protein synthesis (MPS) ${ }^{(197)}$. However, previous reports from animal studies have revealed that GH concentrations are normal $^{(198)}$ or elevated ${ }^{(199)}$, whereas circulating insulin-like growth factor-1 (IGF-1) concentrations is reduced in rodents fed with a $\mathrm{KD}^{(198,200-202)}$. The IGF-1-lowering effects of KD have also been reported in human studies ${ }^{(203,204)}$. These findings suggest that KD might have caused GH resistance, which could have been responsible for the IGF-1 reduction. Third, in most cases, KD are relatively high in protein ${ }^{(205)}$ (approximately 30-35\% of daily energy intake $)^{(206)}$. It has been recently shown that a high-protein diet could preserve muscle mass during $\mathrm{BM}$ and/or fat loss phase ${ }^{(207-211)}$. The conceivable FFM-preserving mechanism of high-protein diets can be related to dietary protein-induced alterations in protein turnover, particularly MPS, inhibiting AMP-activated protein kinase (AMPK) phosphorylation and activating mammalian target of rapamycin complex 1 signalling ${ }^{(158,212-214)}$. However, it seems that, besides these possible FFM-preserving mechanisms, the amount of FFM loss is slightly higher following KD compared with non-KD ${ }^{(29,215,216)}$.

$\mathrm{KD}$ is a strategy often employed by individuals who are endeavouring to lose BM rapidly. It is well established that rapid $\mathrm{BM}$ loss diets are not efficient at preserving $\mathrm{FFM}^{(217-220)}$. Unfortunately, the main contributor to BM loss can be the result of decreased muscle mass, occurring to some extent to support the burden of adipose tissue ${ }^{(221)}$. Following non-KD, in participants with obesity, FFM contributes approximately 20-30\% to total BM loss ${ }^{(69,70,72-75,222,223)}$. It seems that this amount of FFM loss is slightly higher following $\mathrm{KD}^{(215,216,224)}$. This catabolic effect of KD may cause an inhibiting effect on the mechanistic target of rapamycin (mTOR) signalling pathway ${ }^{(225)}$. By inducing a fasting-like state, KD lead to alterations in the metabolic pathways and cellular processes such as autophagy ${ }^{(226)}$. In an animal model, hypercorticosteronaemia and hypoinsulinaemia, along with decreased IGF-1 secretion induced by $\mathrm{KD}$, resulted in muscle atrophy via autophagy, particularly in muscle tissue that can reduce MPS ${ }^{(200)}$. Moreover, the KD 'mimics' energy restriction effects on AMPK, sirtuin-1 (SIRT-1) and PPAR- $\gamma$ coactivator $1-\alpha$ (PGC1- $\alpha$ ), which are activated through phosphorylation and are important regulators of energy metabolism ${ }^{(226)}$. In skeletal muscle, the activation of the AMPK/SIRT-1 pathway promotes fatty acid oxidation but consequently inhibits MPS ${ }^{(227-231)}$. AMPK indirectly activates SIRT-1 in skeletal muscle by increasing $\mathrm{NAD}+{ }^{(24)}$. This is accomplished through the increase in mitochondrial $\beta$-oxidation ${ }^{(228)}$ and thus increased expression of nicotinamide phosphoribosyltransferase, which is the rate-limiting enzyme in NAD+ synthesis ${ }^{(232)}$. Simply stated, the coordinated effects of AMPK and NAD-dependent deacetylase SIRT-1 are primarily mediated by PGC1- $\alpha$, which is activated through phosphorylation of AMPK and deacetylation of SIRT-1 ${ }^{(228,230,233-237)}$. PGC1- $\alpha$ relocates to the nucleus, where it functions as a transcription factor. This increases the expression of genes that code for proteins involved in fatty acid transport, fat oxidation and oxidative phosphorylation. The activation by phosphorylation of PGC1- $\alpha$ may occur in several ways involving AMPK, Ca calmodulin-dependent protein kinase and p38 mitogen-activated 
protein kinase signalling pathways. AMPK can act in two ways: either by activating PGC1- $\alpha$ through phosphorylation or by promoting the expression of enzymes involved in skeletal muscle oxidation and metabolism ${ }^{(238)}$. Additionally, in participants with obesity, skeletal muscle is less oxidative and has lower AMPK activation during the fasting state ${ }^{(239)}$.

At the same time, AMPK activation also inhibits mTOR signalling by boosting Tuberous Sclerosis 2, an antagonist of mTOR signalling activation, which is the most critical signalling mechanism in regulating MPS ${ }^{(240)}$. Although there is some evidence that these changes have health benefit effects such as modulating effects on glucose homoeostasis and insulin action, KD, similar to fasting, blunts the protein kinase $\mathrm{b}(\mathrm{Akt}) / \mathrm{mTOR}$ pathway and reduces the possibility of muscle mass gains despite energy sufficiency ${ }^{(239,240)}$. It is well established that increasing dietary protein intake following exercise interventions, especially resistance training (RT), attenuates BM loss-induced reduction in muscle mass ${ }^{(209,241,242)}$. Dietary interventions that could lead to superior muscle mass retention during BM loss would be beneficial for several reasons, including maintenance of $\mathrm{RMR}^{(243)}$. However, most studies show that KD have no positive effect on preserving FFM than an $\mathrm{LFD}^{(29)}$.

In addition to the molecular pathways involved, another possible explanation is that the body recruits amino acids (through de-amination or transamination) from muscle proteins to maintain blood glucose via gluconeogenesis. Carbohydrate restriction leads to decreases in blood glucose, and it is possible that increased gluconeogenic activity could promote MPB to provide an amino acid substrate. Consequently, the primary fuel for gluconeogenesis is the amino acid pools, along with glycerol derived from $\mathrm{TAG}^{(244)}$. Using amino acids through gluconeogenesis can be a reason for an increase in amino acids released from muscle tissue, resulting in muscle mass decrements ${ }^{(245)}$. While this is known to occur during complete fasting, $\mathrm{KD}$ promote a pseudo-fasted state in which the oxidation of fatty acids primarily meets energy requirements due to the lack of dietary carbohydrates, but catabolism is not as pronounced as during a complete fast ${ }^{(246-248)}$. For instance, it has been reported that young men with obesity lost only $3 \%$ of FFM during a 10-d hypoenergetic $\mathrm{KD}$ than $65 \%$ of BM as FFM during $10-\mathrm{d}$ fasting ${ }^{(246)}$.

Conversely, several investigations found that $\mathrm{KD}$ are more effective in preserving FFM compared with LCD. For instance, Young et al. compared three isoenergetic $(1800 \mathrm{kcal} / \mathrm{d})$ and isonitrogenous $(115 \mathrm{~g} / \mathrm{d})$ dietary interventions that differed in carbohydrate content. After 9 weeks on the 30-g, 60-g and 104-g carbohydrate diets, BM loss was $16.2 \mathrm{~kg}, 12 \cdot 8 \mathrm{~kg}$ and $11.9 \mathrm{~kg}$, respectively, and fat accounted for $95 \%, 84 \%$ and $75 \%$ of the total BM loss, respectively ${ }^{(249)}$. Although these results should be interpreted with caution given the low number of participants, this study strongly suggests that KD promote FM loss while preserving muscle mass compared with LCD. While it seems that KD cause more FFM loss than a high-carbohydrate diet, this finding suggests that compared with LCD, KD may be superior to preserving FFM. Moreover, data from the study by Young et al. provide further evidence that supports the notion that 'a calorie is not a calorie'(141,250,251).

In addition, it has been recently shown that a high-protein diet could preserve muscle mass during BM and/or FM loss phase ${ }^{(207-211)}$. In most cases, a KD consists of a moderate to a high amount of protein, which generally contains animal-based high-protein sources ${ }^{(252)}$; an important factor for dietary proteininduced alterations in protein turnover, particularly MPS, and activating mTOR signalling ${ }^{(157,212-214)}$. It has been mentioned that the plausible FFM-preserving mechanism of high-protein diets can be related to dietary protein-induced alterations in protein turnover, particularly MPS, inhibiting AMPK phosphorylation and activating mTOR signalling ${ }^{(157,212-214)}$. Nevertheless, there are a limited number of studies comparing KD with different protein intakes. However, a KD with $40 \%$ protein maintained muscle mass in community-dwelling elite athletes ${ }^{(253)}$. Therefore, it seems that increasing the proportion of daily protein intake is a practical application for preserving $\mathrm{FFM}^{(254)}$. For example, Volek et al. determined the differences between energy-restricted KD (30\% protein) and LFD (20\% protein) on BM loss and body composition in overweight men and women $^{(167)}$. Although both men and women following KD showed a greater decline in lean mass, the differences were insignificant. Therefore, a KD with correct amounts of protein could help the preservation of FFM. However, it should be considered that exceeding protein consumption could interrupt the ketogenic process.

Positive effects of carbohydrate intake on net muscle protein balance could be another possible mechanism of higher FFM loss in KD. Although it is reported that carbohydrate consumption may not significantly affect MPS ${ }^{(255,256)}$, some previous studies have shown its beneficial effects on net muscle protein balance by reducing MPB ${ }^{(257,258)}$. These positive effects of carbohydrates may be mediated by insulin ${ }^{(256,259-261)}$. The anti-catabolic effect of insulin acting on MPB was confirmed in a systematic review and meta-analysis of forty-four human studies, which concluded that insulin did not significantly affect MPS but had a crucial role in reducing $\mathrm{MPB}^{(262)}$. According to their findings, overall, insulin significantly increased net balance protein acquisition. However, it seems that the anti-catabolic effects of carbohydrates are small compared with protein or protein plus carbohydrate intake ${ }^{(257,263-267)}$.

Alterations in body water during $\mathrm{KD}$ could also cause the differences in lean mass observed ${ }^{(268)}$. Readings from dualenergy X-ray absorptiometry scans and biological impedance (two commonly used methods of assessing body composition) demonstrate fluctuations in body composition that occur following variations in body water content. Furthermore, these methods generally include total body water as a component of lean mass $^{(103,269,270)}$. Therefore, the water loss that typically occurs during the initiation of carbohydrate restriction can result in an incorrect indication of functional muscle mass loss. Yancy et al. showed that within the first 2 weeks of a person adhering to $\mathrm{KD}$, the individual lost a greater amount of water than those who adhered to an LFD. However, after the first 2 weeks, estimations of total body water were similar between groups ${ }^{(130)}$. The authors also reported that FFM changes in both groups were largely explained by changes in total body water but not lean mass tissue.

A longer duration study by Brehm et al. showed that similar to $\mathrm{BM}$ and FM, lean mass decreased more in the KD group compared with the LFD group at both 3 and 6 months. These authors 
also mentioned that it is implausible that differences in BM between the two groups at 3 and 6 months result from extreme changes in body water in the very low-carbohydrate dieters ${ }^{(109)}$. Decreasing energy intake by 500 energy content daily should result in 1 pound $(0.45 \mathrm{~kg})$ per week ${ }^{(271)}$. However, KD typically produce a 2- to 3-kg BM loss in the first week; thus, at least in the early phase of $\mathrm{KD}$, diet-induced diuresis plays a vital role in BM loss ${ }^{(272)}$.

In conclusion, BM loss following $\mathrm{KD}$, like other non-KD, may result in FFM and/or muscle mass reductions. It seems there are no specific advantages for KD compared with high carbohydrate-LFD. Moreover, it seems that this amount of lean mass loss is slightly higher following $\mathrm{KD}$, especially in short-term trials. Activation of AMPK and inhibition of mTOR signalling, inducing gluconeogenesis, increasing the net balance protein acquisition, and diuresis may be the possible mechanisms of lean mass loss in individuals adhering to $\mathrm{KD}$. However, increasing the portion of protein in KD may be a practical approach for preserving muscle mass following the BM loss phase. However, it should be considered that protein intake does not have to notably modify the level of glycaemia and insulinaemia with the risk to exit the status of ketosis: a sufficient level of ketonaemia is a mandatory condition for a successful KD. It seems that the short-term adverse effects of KD on FFM are because of body water reduction. However, muscle mass reduction following long-term adherence to KD may not be related to body water. Further research is needed to determine whether the effect of KD in individuals following this dietary approach. In addition, possible mechanisms underlying the effects of KD on FFM should also be examined.

\section{Sex-specific effects of ketogenic diets on body composition}

Although there is evidence outlining the beneficial effects of $\mathrm{KD}$ on BM and/or fat loss, little is known about the effect of sex differences on body composition changes induced following a KD. The sex-specific impact of different dietary interventions is important because it is generally more difficult for females to lose $\mathrm{BM}^{(273)}$. Females are also likely to lose less $\mathrm{BM}$ than males during a dietary intervention ${ }^{(273)}$, although they are more likely to adopt and adhere to a diet initially ${ }^{(274)}$. Although some evidence suggests sex-specific effects of KD in animal studies ${ }^{(275,276)}$, findings of the sex differences in body composition changes induced by KD in humans are limited. However, like other dietary interventions, KD may be more beneficial in men than women. For example, Lyngstad et al. compared body composition changes following 13 weeks of $\mathrm{KD}$ in men and women. According to their findings, males had a greater BM ( $\mathrm{kg}$ and \%) and FM loss than females at week 9 (BM: $17 \%$ and $20.6 \mathrm{~kg}$ BM loss in men compared with $15 \%$ and $15.3 \mathrm{~kg}$ BM loss in women, FM: $15.5 \mathrm{~kg}$ FM loss in men compared with $12 \cdot 2 \mathrm{~kg}$ FM loss in women) ${ }^{(277)}$. These differences were also apparent at week 13, with males achieving a greater reduction in BM, FM and FFM (from baseline) than females.

Interestingly, although it has been suggested that females are also likely to lose more FFM than males during BM loss, Lyngstad et al. showed that men lost more FFM at both weeks $9(4.9 \mathrm{~kg} v$.
$3 \cdot 1 \mathrm{~kg}$ FFM loss in men and female, respectively) and $13(3.2 \mathrm{~kg} v$. $1.8 \mathrm{~kg}$ FFM loss in men and female, respectively) ${ }^{(277)}$. In another study by D'Abbondanza et al., the authors reported that men seem to experience larger benefits than females in BM and FM loss after $25 \mathrm{~d}$ following a KD. In terms of FFM changes, no sex-specific differences were observed. In an isoenergetic study with a moderate energy restriction of about $30 \%$ of energy, Brinkworth et al. compared sex-specific differences following 8 weeks of a $\mathrm{KD}^{(278)}$. According to the results, males had a greater $\mathrm{BM}$ and FM loss than females (BM: $10 \mathrm{~kg}$ BM loss in men compared with $7.4 \mathrm{~kg}$ BM loss in women, FM: $8.2 \mathrm{~kg}$ FM loss in men compared with $5.2 \mathrm{~kg}$ FM loss in women). However, FFM decreased during both interventions at a similar amount $(2 \mathrm{~kg}$ FM loss in men compared with $2 \cdot 2 \mathrm{~kg}$ FM loss in women), with no effect of diet or sex.

Moreover, Volek et al. revealed that BM, FM and trunk FM reductions were significantly greater after a KD than the LFD for men but not for women ${ }^{(167)}$. Although KD' sex-specific mechanisms of action are unclear, higher basal energy expenditure because of higher FFM in men may be the main cause of these differences $^{(279)}$. In contrast to these findings, Gu et al. showed similar beneficial effects of KD on body composition in both sexes $^{(175)}$. Further studies are needed to evaluate the sex-specific effects of KD on body composition.

\section{Effects of ketogenic diet and exercise on body composition}

It is well-documented that exercise intervention can improve body composition, including decreasing FM and/or preserving or increasing lean mass in different populations ${ }^{(280-284)}$. Effects of exercise on body composition are mainly accounted for by regulation of genes, hormone concentrations (e.g. testosterone, IGF-1) and metabolic pathways (especially by activating the mTOR signalling) ${ }^{(285-287)}$. Although professional organisations have historically focused on endurance or aerobic trainingbased guidelines for BM loss and maintenance ${ }^{(288)}$, recent guidelines and position statements targeting BM reduction and maintenance have suggested that RT may also be effective for reducing $\mathrm{FM}^{(289)}$. Moreover, $\mathrm{RT}$ results in superior improvements in muscle mass and muscular strength ${ }^{(290,291)}$.

Numerous studies have demonstrated various macronutrient ratios on body composition in trained populations ${ }^{(8,292-294)}$. Existing sports nutrition guidelines propose carbohydrate-based or periodised carbohydrate-based diets to augment muscular adaptations to exercise ${ }^{(295-297)}$. Carbohydrate feeding may play an important role in improving body composition and recovery in endurance and resistance-trained individuals ${ }^{(298,299)}$. For example, in resistance-trained individuals, carbohydrates are suggested to augment muscle development via an increased insulin response. Specifically, insulin promotes anti-catabolic effects on muscle, thereby shifting protein balance to favour anabolism ${ }^{(300)}$. Co-infusion of amino acids and insulin increases amino acid delivery to muscle ${ }^{(301-303)}$, and it may increase MPS $^{(262)}$. Findings from a study by Bird et al. indicated that 12 weeks of carbohydrate plus essential amino acid ingestion enhances muscle anabolism following RT to a greater extent than either carbohydrate or essential amino acids consumed 
independently ${ }^{(304)}$. However, in the last few years, there has been a surge in popularity in low-carbohydrate and high-fat approaches such as KD due to its purported beneficial effects on body composition ${ }^{(29,238)}$. Like untrained individuals, a KD may be an effective BM and FM loss strategy in athletes ${ }^{(305)}$. Mainly, in trained individuals, anti-obesity benefits of KD were shown in ad libitum studies ${ }^{(306,307)}$. The BM and/or FM loss may likely be explained by a resultant energy deficit created by the KD, as enhanced feelings of satiety and a reduction in overall food intake ${ }^{(306)}$. However, some evidence suggests that following a KD combined with exercise resulted in more fat oxidation and more ATP production from fat ${ }^{(308,309)}$. These findings underline the efficacy of KD on mitochondrial function and efficiency towards fat oxidation in athletes. However, there are still some concerns about FFM decrement in athletes performing high-intensity exercises ${ }^{(310,311)}$. In regard to the effects of a combination of exercise with a KD on adiposity, studies showed more efficacy of KD in BM and FM loss, especially in ad libitum conditions $^{(312-315)}$.

The KB, BHB and AcAc are optimal substrates for muscle tissue and are rapidly oxidised. Unlike severe energy restrictions, KD provide adequate amounts of energy and protein to athletes. Therefore, KD avoid protein deficiency but induce a 'fasting-like' state, leading to alterations in the metabolic pathways ${ }^{(238,253)}$ Although both fasting and KD result in glycogen depletion and increased serum FFA, physiological adaptations following a KD are different from fasting. Losses of the magnitude encountered in fasting cannot be accounted for by adipose tissue breakdown alone and more likely represent significant lean tissue catabolism $^{(246)}$. Since KB plays an essential role in regulating muscle substrate utilisation, these differences may cause differences in $\mathrm{KB}$ concentrations ${ }^{(316-318)}$. KB exert a restraining effect on $\mathrm{MPB}^{(205)}$. Thomsen et al. reported that BHB has potent anti-catabolic effects in muscle at the whole-body level; in muscle, reduction of MPB overrides inhibition of $\mathrm{MPS}^{(188)}$. Besides the dietary interventions, prolonged physical exercise performed in a fasted state also stimulates ketogenesis and results in post-exercise hyperketonaemia ${ }^{(319-321)}$. For example, $\mathrm{KB}$ concentrations can reach about $0.5-1.0 \mathrm{mmol} / \mathrm{l}$ in response to $2 \mathrm{~h}$ of exercise performed in an overnight fasted state and subsequently increase to about $1-4 \mathrm{mmol} / 1$ during early postexercise recovery ${ }^{(321-323)}$. The extent of exercise-induced hyperketonaemia during and after exercise is influenced by the intensity and volume of the exercise performed, as well as nutritional status ${ }^{(319,320)}$. Alternative fuelling strategies, based on adaptation to a KD, increase fat oxidation during exercise and might help spare the body's limited glycogen stores $^{(324)}$. In addition, KD have been used to increase fat oxidation during exercise. This also increases the production of $\mathrm{KB}$, which may provide an additional energy substrate for the brain and muscle tissue ${ }^{(325)}$.

Moreover, higher quality and quantity of protein stimulated $\operatorname{MPS}^{(326-329)}$. It is well established that muscle mass gains depend highly on a net balance between MPS and MPB ${ }^{(330)}$. Therefore, besides the similarities between KD and fasting, a KD could positively affect muscle mass by decreasing MPB while stimulating MPS to a greater extent than fasting.
However, it seems that KD are not substituted for a highcarbohydrate diet regarding preserving muscle mass.

In summary, KD can be a practical approach for BM and FM loss in both resistance and endurance-trained individuals. However, its effects on muscle mass depending on the type and intensity of training employed. Later, in this paper, we will enlarge on body composition changes in RT and endurance training (ET) athletes adhered to KD.

\section{Resistance training}

KD combined with RT interventions may increase the rate of FM loss in athletes, but compared with non-KD, it is not an appropriate dietary approach for increasing muscle mass. While KD may be helpful in endurance performance ${ }^{(191,331)}$ by increasing fat oxidation capacity ${ }^{(309,332)}$ (especially in long-distance events lasting from 2 to $5 \mathrm{~h}$ ), it is an oxymoron when athletes seek to boost muscle hypertrophy ${ }^{(238)}$. Previous animal studies suggested that KD might impair the balance between anabolic and catabolic pathways within skeletal muscle. For instance, Kennedy et al. reported that mice fed with a low-energy KD (79\% of fat, $10 \%$ of protein) over 9 weeks exhibited $17 \%$ lower absolute lean mass compared with mice fed a standard chow diet ( $6 \%$ of fat, $24 \%$ of protein) ${ }^{(333)}$. They also showed that KD feeding is associated with a two-fold increase in AMPK in the liver and more than a three-fold increase in the soleus muscle.

Moreover, Frommelt et al. reported that two KD consisting of $75 \%$ fat, $10 \%$ protein, $65 \%$ of fat, $20 \%$ of protein, reduced whole-body nitrogen balance and carcass protein content in rats compared with those fed a standard chow diet (5\% of fat and $21 \%$ of protein) after 4 weeks $^{(334)}$. Furthermore, it has been reported that the KD inhibits the mTOR signalling pathway by reducing the expression of Ribosomal protein $\mathrm{S} 6$ kinase beta-1 and $\mathrm{Akt}^{(225)}$. These findings have led others to contend that increased KD-induced skeletal muscle AMPK activation may blunt anabolic mTOR signalling despite energy sufficiency ${ }^{(238)}$. Indeed, this hypothesis is supported by several human studies that have reported that chronic KD result in attenuated muscle mass. For example, Volek et al. reported that despite a KD significantly reducing whole-body and abdominal fat over 12 weeks, lean mass also declined by $3.4 \mathrm{~kg} v .1 .0 \mathrm{~kg}$ in participants who were placed on $\mathrm{LFD}^{(335)}$. Noakes et al. also showed that a $\mathrm{KD}$ reduced lean mass by $2.6 \mathrm{~kg}$ over 12 weeks ${ }^{(215)}$. However, it should be noted that equivocal reports suggested that KD do not affect muscle mass ${ }^{(253,336,337)}$. It should be mentioned that higher BM decrements can result in higher FFM loss, and therefore, higher FFM loss may be the result of more BM loss during KD. In this situation, FFM percentage changes can be a more reliable index for the FFM-preserving effects of KD. Therefore, future studies should focus more on FFM percentage changes to evaluate KD' effects on lean mass changes.

While it has been reported that KD result in a decrease in lean mass, there is limited evidence to suggest that a KD combined with RT may be beneficial for attenuating the decrease in lean mass. For instance, Jabekk et al. reported that while RT on a regular diet may increase lean mass without significantly affecting FM, RT combined with a KD may reduce FM without negatively 
affecting lean mass ${ }^{(312)}$. It has been revealed that adopting a KD with RT causes marked reductions in whole-body adiposity while not impacting lean mass ${ }^{(338)}$. In contrast, most studies reported a significant decrease in FFM following a KD with RT. In a crossover study, the KD ( $\leq 50 \mathrm{~g}$ or $\leq 10 \%$ daily intake of carbohydrates) phase resulted in significantly lower BM $(3.26 \mathrm{~kg}, P=0.038)$ and lean mass $(2.26 \mathrm{~kg}, P=0.016)$ compared with the ad libitum usual diet ( $>250 \mathrm{~g}$ daily intake of carbohydrate $)^{(14)}$. In addition, results from a study by Wood et al. indicated that a KD without exercise led to less FFM loss than an LFD and similar losses compared with an LFD combined with $\mathrm{RT}^{(339)}$. More recently, Vargas-Molina et al. found that in an ad libitum condition, a KD helped decrease more FM compared with a non-KD after 8 weeks of RT in trained women $(-1 \cdot 1 v$. $0.3 \mathrm{~kg}$ ). However, absolute changes were more favoured for non-KD $(-0.7 v .0 .7 \mathrm{~kg})^{(340)}$. Moreover, in another ad libitum study using US military personnel, KD combined with RT showed a remarkable BM loss compared with a normal mixed diet $(-7 \cdot 7 \mathrm{~kg} v \cdot 0 \cdot 1 \mathrm{~kg})$. FM and BFP decreased in KD compared with non-KD (-5.9 $\mathrm{kg} v .-0.6 \mathrm{~kg}$ and $-5.1 \% v .-0.7 \%$, respectively). However, lean mass decreased in $\mathrm{KD}$, while non-KD participants gained weight $(-1.4 v \cdot 0 \cdot 8 \mathrm{~kg})^{(310)}$. One possible reason that $\mathrm{KD}$ failed to adopt during $\mathrm{RT}$ is that during high-intensity exercise, the rate of ATP breakdown is too high to be matched by the rate of ATP production from FFA ${ }^{(341)}$. This phenomenon limits the use of fat loading in sport disciplines that require highintensity efforts from the athletes. High-intensity exercise also suppresses lipolysis, thereby reducing the availability of fatty acids to the muscle ${ }^{(342)}$. An increased rate of glycolysis and lactate production during exercise also hinders fat oxidation by reducing the entry of long-chain fatty acids into the mitochondria ${ }^{(343)}$. On the other hand, Wilson et al.'s study is the only study that reported an increase in FFM after 10 weeks of KD and 2 weeks of carbohydrate reintroduction in resistance-trained males ${ }^{(344)}$. However, it seems that muscle mass increments in the Wilson et al. study were because of a 2-week carbohydrate loading, which strongly suppressed the Tuberous Sclerosis 2 protein as an antagonistic of mTOR signalling activation. It is important to note that the evaluation of FFM by Dual-energy X-ray absorptiometry includes intracellular water, which is stored in concert with muscle glycogen in a about 3:1 ratio ${ }^{(159)}$. Thus, another reason for increasing FFM following 2 weeks of carbohydrate refeed to the 10 weeks of KD in the study by Wilson et al. maybe because of increasing intracellular water which can positively influence final FFM results. Almost all of the research reported a decrease or no significant changes in FFM following a KD combined with RT. It seems that increasing protein intake preserves lean mass in resistance-trained individuals adhering to KD. Studies that reported similar (non-significant) changes in lean mass, consumed higher protein intakes in $\mathrm{KD}$ group $(\approx 17-58 \%$ or $18-118 \mathrm{~g}$ more protein intake in $\mathrm{KD}$ group $)^{(253,312,313,315,339,345)}$. However, in the study by Vargas-Molina et al., higher protein intake (115 v. $97 \mathrm{~g}$ in KD and non-KD group, respectively) in KD could not help muscle mass preservation and there was a significant lean mass loss following $\mathrm{KD}^{(340)}$. In another study, Paoli et al. reported that $\mathrm{KD}$ may be used with the caution during body building preparation because it can blunt hypertrophic responses ${ }^{(346)}$. Recently, Vidic et al. compared the effects of two isoenergetic hypoenergetic ketogenic hyper-ketonaemic and non-ketogenic low-carbohydrate high-fat high cholesterol diets on body composition in strength-trained middle-aged men ${ }^{(347)}$. Based on their findings, these two diets have a similar impact on body composition. A recent meta-analysis of thirteen randomised controlled trial by Ashtary-Larky et al. showed that a combination of RT with KD was associated with declines in all body composition indices, including BM, BMI, FM, BFP and $\mathrm{FFM}^{(108)}$. Based on the results derived from this meta-analysis, although KD resulted in more $\mathrm{BM}$ and FM loss, significant changes in these two indices occurred only in ad libitum studies but not in isoenergetic studies. Although all included studies in the analysis lasted $<3$ months, the pooled results demonstrated that KD interventions resulted in $1.26 \mathrm{~kg}$ of FFM loss. Surprisingly, the amount of BM and FM loss was 3.67 and $2 \cdot 21$, respectively. These findings suggested that one-third (34\%) of BM loss in individuals performing RT may be from FFM.

In conclusion, it seems that KD may be a practical dietary approach for reducing BM and FM. In ad libitum studies, KD resulted in more BM and FM loss in resistance-trained individuals $^{(312,313)}$. However, these advantages did not report in nonad libitum studies (same energy restriction in both $\mathrm{KD}$ and non-KD groups $)^{(339,345)}$. Moreover, there are some concerns about FFM decreasing in RT athletes who adhered to a KD in both ad libitum and non-ad libitum conditions. KD-induced skeletal muscle AMPK activation, which blunt anabolic mTOR signalling, may be a possible mechanism of lean mass loss in KD. Higher protein intakes may be beneficial to lean mass preservations in resistance-trained individuals following a KD. Further longer-term research is needed to determine the effects of KD on resistance-trained individuals.

\section{Endurance training}

Under usual dietary conditions, athletes utilise carbohydrates as their predominant fuel source following high-volume $\mathrm{ET}^{(296)}$. However, it is well established that ET can increase lipolysis and help decrease FM during the BM loss phase ${ }^{(348,349)}$. Since the body can metabolise fat more efficiently during $\mathrm{ET}^{(350)}$, KD could efficiently prepare carbohydrates and promote fat oxidation ${ }^{(351)}$. There is robust evidence that substantial increases in fat oxidation occur, even in elite endurance athletes, within 3-4 weeks and possibly $5-10 \mathrm{~d}$ of adherence to a $\mathrm{KD}^{(352-355)}$. Previous studies involving KD have reported increases in intramuscular TAG ${ }^{(356)}$, hormone-sensitive lipase ${ }^{(357)}$, expression of fatty acid translocase FAT/CD36 protein $^{(358)}$ and carnitine palmitoyltransferase ${ }^{(359)}$. Collectively, these changes suggest increases in fat availability, mobilisation and transport activities within the complex regulation of fat utilisation by muscle tissue (357,358,360). $^{\text {. }}$ Even short-term interventions have shown a reduction in respiratory exchange ratio during exercise, and it generally indicates enhanced fat oxidation ${ }^{(361)}$. A reduced respiratory exchange ratio has been considered a metabolic benefit of $\operatorname{LCD}^{(361,362)}$. However, compared with long-term studies, short-term 
investigations show less substantial effects on body composition, likely due to the absence of keto-adaptation ${ }^{(363)}$.

In a prospective, randomised, 2-week pilot study, compared with non-KD, adhering to a KD combined with ET failed to show significant improvements in body composition ${ }^{(361)}$. In an isoenergetic study with a moderate energy restriction of about $30 \%$ of energy, Brinkworth et al. reported a slightly higher but significant BM loss in the KD group compared with a high-carbohydrate group $(-8.1$ and $-6.7 \mathrm{~kg}$, respectively) for 8 weeks ${ }^{(278)}$. Authors also reported similar BM loss in both diet groups for women but greater BM loss in KD than in highcarbohydrate groups for men. Similarly, there was a greater reduction in FM in men consuming the $\mathrm{KD}$ than the highcarbohydrate diet, but similar reductions for both diet groups in women. Finally, FFM decreased during both interventions at a similar amount, with no effect of diet or sex. In another study by Burke et al., BM decreased over the 3 weeks of intensified training and a mild energy deficit, with losses being greater in the KD group than the high-carbohydrate diet group $^{(353)}$. Compared with a high-carbohydrate diet, the authors also reported that the KD was associated with the highest rates of whole-body fat oxidation ever reported across exercise of varying speeds and intensities. There is evidence that those who adhered to a KD comfortably exceeded the time frame shown to produce robust cellular adaptations to 'retool' the muscle to increase its capacity for fat oxidation $^{(314)}$. Dostal et al. showed that 12 weeks of a KD resulted in more BM, FM and BFP decrements without any significant changes in FFM in recreationally trained individuals performing interval training and home-based and endurance-type (e.g., running, cycling, sports games) exercises ${ }^{(315)}$. In an $a d$ libitum study by McSwiney et al., 12 weeks of KD showed a significantly greater decrease in BM $(-0.8 v \cdot-5.9 \mathrm{~kg})$ and BFP $(-0 \cdot 7 \%, v .-5 \cdot 2 \%)$ without any changes in lean mass $(+0 \cdot 1 v$. $+0.3 \mathrm{~kg}$ ) compared with a non-KD in endurance-trained men ${ }^{(314)}$. A single-arm, before-and-after comparison study consisting of a 6-week KD, Urbain et al. revealed that a combination of ET with KD was associated with declines in all body composition indices, including BM, FM and FFM in healthy adults participating in aerobic exercises ${ }^{(203)}$.

However, because of the absence of a control group, these findings should be interpreted with caution. Furthermore, McSwiney et al. investigated the effects on substrate utilisation during incremental exercise and changes in body composition in response to $7 \mathrm{~d}$ ad libitum consumption of a KD by athletes in endurance sports ${ }^{(364)}$. Their finding suggested higher fat oxidation, $76 \%$ of BM loss was from FFM decrement $(-1.82 \mathrm{~kg}$ FFM and $-2 \cdot 4 \mathrm{~kg}$ BM-loss). However, a high FFM loss in this shortterm study may be attributed to diet-induced diuresis following keto-adaptation. The body can use more fat as fuel while freeing itself from degrading muscle and liver glycogen at high rates $^{(365)}$. In an animal study, Ma et al. evaluated the effects of an 8-week intervention of a KD and running on a treadmill using mice ${ }^{(366)}$. They found that the KD may potentially prevent muscle damage by altering the IL-6 secretion. These results suggested that a long-term KD, which warrants keto-adaptation, could be a valuable aid to endurance athletes to improve body composition by decreasing BM and body fat while possibly preserving lean mass.

It seems that the beneficial effects of KD on body composition and endurance performance in endurance-trained individuals are due to greater fat oxidation during exercise ${ }^{(367-370)}$. The appeal of KD for endurance athletes is likely due to the shift in fuel utilisation, from a carbohydrate-based model to one that utilises fat primarily, of which stores are virtually unlimited compared with carbohydrates (i.e. muscle glycogen) ${ }^{(306)}$. This metabolic shift was observed after a period of KD adhering almost named 'fat-adapted,' which has been well-documented in studies since the $1980 \mathrm{~s}^{(371)}$. These adaptations may be the reason for the advantageous effects of KD on FM in endurance-trained athletes ${ }^{(112)}$. High-fat KD may require a significant amount of time for adaption in endurance-trained individuals ${ }^{(372)}$. It is common for individuals to report fatigue and energy deficiency in the first few weeks after adopting a $\mathrm{KD}^{(373)}$. Volek et al. have indicated that several months may be necessary for adaptation, fatigue symptoms to subside and adjustments in glycogen homoeostasis ${ }^{(363)}$. These could be potential mechanisms for longer-term studies that showed improvements in body composition and endurance performance in endurance-trained individuals.

During exercise, fat is recruited in the form of FFA (and albumin-bound FA), as very-LDL-TAG, and from muscle tissue as TAG (either from intra- or extracellular stores) ${ }^{(374)}$. Seven days following the start of a KD combined with ET, TAG-derived fatty acid oxidation (very-LDL or intramuscular TAG) plays a role in increasing fat oxidation and plasma-derived fatty acids remain the major source for fat oxidation ${ }^{(375)}$. After a 7-week adaptation to the diet and training ( $1 \mathrm{~h}$ of exercise at $50 \%$ of maximal power output), increases in fat oxidation were derived from increased utilisation of very-LDL-TAG, plasma fatty acids ${ }^{(369)}$. In addition, it has been shown that high-fat diet-induced increases in muscle lipoprotein lipase activity ${ }^{(376)}$. Accordingly, it could be suggested that, during exercise, fat recruited from both plasma NEFA and plasma very-LDL-TAG is responsible for the increased fat oxidation after long-term high-fat diet adaptation. Intriguingly, muscle TAG utilisation is not increased after a high-fat diet considering that high dietary fat content would lead to increased muscle TAG storage, and vice versa a low dietary fat content results in decreased muscle TAG storage ${ }^{(377,378)}$.

Interestingly, it seems that muscle glycogen is not different following KD and high-carbohydrate diets. Volek et al. compared the metabolic adaptations in elite ultra-marathoners and ironman distance triathletes following a 20-month $\mathrm{KD}$ and high-carbohydrate $\operatorname{diet}^{(363)}$. They showed that muscle glycogen was significantly decreased by $62 \%$ immediately post-exercise (a 180 min submaximal run at $64 \% \mathrm{VO}_{2}$ max on a treadmill) and $38 \%$ at $2 \mathrm{~h}$ post-exercise in the high-carbohydrate diet group, while in the KD group, muscle glycogen was decreased by $66 \%$ immediately post-exercise and $34 \%$ at $2 \mathrm{~h}$ post-exercise. In contrast, two-fold higher rates of peak fat oxidation were detected during graded exercise in the KD group, greater capacity to oxidise fat at higher exercise intensities and two-fold higher rates of fat oxidation during sustained submaximal running ${ }^{(363)}$. Besides, the effects of KD combined with ET on body composition and the impact of carbohydrate loading are unclear. Only 
one study investigated 7-d carbohydrate loading following $\mathrm{KD}$ and increased BM, FFM and FM, which may be related to the increased blood concentration of insulin and glucose responsible for increasing the rate of lipogenesis, as shown through increased $\mathrm{BM}$ and $\mathrm{FM}^{(379)}$. It seems that increments in FFM after the 7-d carbohydrate loading procedure were most likely due to the increased carbohydrate intake and greater synthesis and storage of muscle glycogen ${ }^{(380)}$.

Regarding high-intensity interval training (HIIT), there is limited data about KD' effects in individuals performing HIIT. In an ad libitum study, Cipryan et al. evaluated the effects of altering from a habitual mixed Western-based diet to a KD over a 4 -week time course during HIIT $^{(381)}$. BM ($4.7 v .-0.8 \mathrm{~kg})$ and $\operatorname{BFP}(-3.2 v .-1.1 \%)$ decreased more in the KD trial. Moreover, in a crossover study, Gyorkos et al. determined the influences of a KD with and without HIIT exercise in participants with the metabolic syndrome ${ }^{(382)}$. Their findings showed that KD with and without HIIT significantly improved body composition by decreasing BM, BFP and waist circumference compared with baseline. However, the addition of HIIT to KD improved body composition (BM, BFP and waist circumference) more than following a diet alone. To the best of our knowledge, there is no study to determine the effects of a KD combined with HIIT on lean mass. Since the impact of a KD combined with HIIT has not been adequately studied, further studies are needed.

Studies suggested that KD are a practical dietary approach for improving body composition in ET athletes by decreasing BM and FM while probably preserving FFM. According to current evidence, it seems that the FFM-preserving effects of $\mathrm{KD}$ are more efficient in endurance-trained than resistance-trained individuals. It also appears that the beneficial effects of KD on body composition in endurance-trained individuals are due to shifting fuel utilisation toward greater fat oxidation during exercise, which occurred after adaptation to a KD. These findings underlined better adaptation of KD in endurance-trained individuals.

\section{Conclusions}

A KD may help improve body composition by decreasing BM and body fat by controlling hunger and improving fat oxidation in both individuals with obesity in athletic populations. Regarding BM and body fat loss effects of KD, KD do not have any superior benefit than non-KD in individuals with obesity and athletes in an isoenergetic situation. In sedentary individuals with obesity, it seems that FFM changes appear to be as great, if not greater, than decreases following an LFD. However, there are some concerns regarding the FFM decrement in individuals following $\mathrm{KD}$, especially in resistancetrained athletes. Moreover, the FFM-preserving effects of $\mathrm{KD}$ are more efficient in athletes performing ET compared with resistance-trained individuals. Future well-controlled research (isoenergetic and iso-protein) should be conducted in participants of different ages and various training experiences (e.g. novice, trained or elite).

\section{Acknowledgements}

No funds received.

D. A. L. and R. B. conceived and designed the research. D. A. L., R. B. and H. B. wrote the manuscript. J. S. B., T. M., L. M. and A.

P. revised the manuscript. All authors read and approved the manuscript.

The authors declare no conflicts of interest.

\section{References}

1. WHO (2016) Global Health Observatory (GHO) data.

2. Han TS \& Lean ME (2016) A clinical perspective of obesity, metabolic syndrome and cardiovascular disease. JRSM Cardiovasc Dis 5, 2048004016633371.

3. Goodwin PJ \& Chlebowski RT (2016) Obesity and cancer: insights for clinicians. J Clin Oncol 34, 4197-4202.

4. Mokdad A, Ford E, Bowman B, et al. (2003) Prevalence of obesity, diabetes, and obesity-related health risk factors, 2001. JAMA 289, 76-79.

5. Oh R \& Uppaluri KR (2020) Low Carbohydrate Diet. StatPearls. StatPearls Publishing.

6. Harvey CJ, Schofield GM, Zinn C, et al. (2019) Low-carbohydrate diets differing in carbohydrate restriction improve cardiometabolic and anthropometric markers in healthy adults: a randomised clinical trial. Peerj 7, e6273.

7. Goldenberg JZ, Day A, Brinkworth GD, et al. (2021) Efficacy and safety of low and very low carbohydrate diets for type 2 diabetes remission: systematic review and meta-analysis of published and unpublished randomized trial data. BMJ 372, m4743.

8. Aragon AA, Schoenfeld BJ, Wildman R, et al. (2017) International society of sports nutrition position stand: diets and body composition. J Int Soc Sport Nutr 14, 16.

9. Paoli A (2014) Ketogenic diet for obesity: friend or foe? Int J Environ Res Public Health 11, 2092-2107.

10. Lu M, Wan Y, Yang B, et al. (2018) Effects of low-fat compared with high-fat diet on cardiometabolic indicators in people with overweight and obesity without overt metabolic disturbance: a systematic review and meta-analysis of randomised controlled trials. Br J Nutr 119, 96-108.

11. Lazarus Yaroch A, Colón-Ramos U \& Atienza A (2008) Awareness, use, and perceptions of low-carbohydrate diets. Prev Chronic Dis 5, A130.

12. Churuangsuk C, Griffiths D, Lean ME, et al. (2019) Impacts of carbohydrate-restricted diets on micronutrient intakes and status: a systematic review. Obes Rev 20, 1132-1147.

13. Jallinoja P, Niva M, Helakorpi S, et al. (2014) Food choices, perceptions of healthiness, and eating motives of selfidentified followers of a low-carbohydrate diet. Food Nutr Res 58, 23552.

14. Greene DA, Varley BJ, Hartwig TB, et al. (2018) A low-carbohydrate ketogenic diet reduces body mass without compromising performance in powerlifting and olympic weightlifting athletes. $J$ Strength Condit Res 32, 3373-3382.

15. Paoli A, Rubini A, Volek J, et al. (2013) Beyond weight loss: a review of the therapeutic uses of very-low-carbohydrate (ketogenic) diets. Eur J Clin Nutr 67, 789.

16. Bueno NB, de Melo ISV, de Oliveira SL, et al. (2013) Very-lowcarbohydrate ketogenic diet $\mathrm{v}$. low-fat diet for long-term weight loss: a meta-analysis of randomised controlled trials. Br J Nutr 110, 1178-1187. 
17. Willoughby D, Hewlings S \& Kalman D (2018) Body composition changes in weight loss: strategies and supplementation for maintaining lean body mass, a brief review. Nutrients $\mathbf{1 0}$, 1876

18. Mohorko N, 囚erneli冈-Bizjak M, Poklar-Vatovec T, et al. (2019) Weight loss, improved physical performance, cognitive function, eating behavior, and metabolic profile in a 12 -week ketogenic diet in obese adults. Nutr Res 62, 64-77.

19. Kirkpatrick C, Bolick J, Kris-Etherton P, et al. (2019) Review of current evidence and clinical recommendations on the effects of low-carbohydrate and very-low-carbohydrate (including ketogenic) diets for the management of body weight and other cardiometabolic risk factors: a scientific statement from the National Lipid Association Nutrition and Lifestyle Task Force. J Clin Lipidol 13, 689-711.

20. Winesett SP, Bessone SK \& Kossoff EH (2015) The ketogenic diet in pharmacoresistant childhood epilepsy. Expert Rev Neurother 15, 621-628.

21. Newburgh L \& Marsh PL (1920) The use of a high fat diet in the treatment of diabetes mellitus: first paper. Arch Internal Med 26, 647-662.

22. Wilder RM (1921) The effects of ketonemia on the course of epilepsy. Mayo Clin Proc 2, 307-308.

23. Masood W \& Uppaluri KR (2019) Ketogenic Diet. StatPearls. StatPearls Publishing.

24. Miller VJ, Villamena FA \& Volek JS (2018) Nutritional ketosis and mitohormesis: potential implications for mitochondrial function and human health. I Nutr Metab 2018, 5157645 .

25. Urbain P, Strom L, Morawski L, et al. (2017) Impact of a 6-week non-energy-restricted ketogenic diet on physical fitness, body composition and biochemical parameters in healthy adults. Nutr Metab 14, 17.

26. D’Andrea-Meira I, Krüger LT, Romão T, et al. (2019) Ketogenic diet and epilepsy: what we know so far. Front Neurosci 13, 5.

27. Krebs HA (1966) The regulation of the release of ketone bodies by the liver. Adv Enzyme Regul 4, 339-354.

28. Fedorovich SV, Voronina PP \& Waseem TV (2018) Ketogenic diet $v$. ketoacidosis: what determines the influence of ketone bodies on neurons? Neural Regener Res 13, 2060.

29. Tinsley GM \& Willoughby DS (2016) Fat-Free mass changes during ketogenic diets and the potential role of resistance training. Int J Sport Nutr Exercise Metab 26, 78-92.

30. Masino SA (2016) Ketogenic Diet and Metabolic Therapies: Expanded Roles in Health and Disease. Oxford University Press.

31. Bergqvist AG, Schall JI, Gallagher PR, et al. (2005) Fasting $v$. gradual initiation of the ketogenic diet: a prospective, randomized clinical trial of efficacy. Epilepsia 46, 1810-1819.

32. Kossoff EH, Cervenka MC, Henry BJ, et al. (2013) A decade of the modified Atkins diet (2003-2013): results, insights, and future directions. Epilepsy Behav 29, 437-442.

33. Kossoff EH \& Hartman AL (2012) Ketogenic diets: new advances for metabolism-based therapies. Curr Opin Neurol 25, 173.

34. Caprio M, Infante M, Moriconi E, et al. (2019) Very-low-calorie ketogenic diet (VLCKD) in the management of metabolic diseases: systematic review and consensus statement from the Italian Society of Endocrinology (SIE). J Endocrinol Investig 42, 1365-1386.

35. Neth BJ, Mintz A, Whitlow C, et al. (2020) Modified ketogenic diet is associated with improved cerebrospinal fluid biomarker profile, cerebral perfusion, and cerebral ketone body uptake in older adults at risk for Alzheimer's disease: a pilot study. Neurobiol Aging 86, 54-63.
36. Nagpal R, Neth BJ, Wang S, et al. (2019) Modified Mediterranean-ketogenic diet modulates gut microbiome and short-chain fatty acids in association with Alzheimer's disease markers in subjects with mild cognitive impairment. EBioMedicine 47, 529-542.

37. Perez-Guisado J \& Munoz-Serrano A (2011) The effect of the Spanish Ketogenic Mediterranean Diet on nonalcoholic fatty liver disease: a pilot study. J Med Food 14, 677-680.

38. Perez-Guisado J \& Munoz-Serrano A (2011) A pilot study of the Spanish Ketogenic Mediterranean Diet: an effective therapy for the metabolic syndrome. $J$ Med Food 14, 681-687.

39. Perez-Guisado J, Munoz-Serrano A \& Alonso-Moraga A (2008) Spanish Ketogenic Mediterranean Diet: a healthy cardiovascular diet for weight loss. Nutr J 7, 30 .

40. Perng BC, Chen M, Perng JC, et al. (2017) A keto-mediet approach with coconut substitution and exercise may delay the onset of alzheimer's disease among middle-aged. J Prev Alzheimers Dis $\mathbf{4}, 51-57$.

41. Paoli A, Bianco A, Grimaldi KA, et al. (2013) Long term successful weight loss with a combination biphasic ketogenic mediterranean diet and mediterranean diet maintenance protocol. Nutrients 5, 5205-5217.

42. Paoli A, Cenci L, Fancelli M, et al. (2010) Ketogenic diet and phytoextracts Comparison of the efficacy of Mediterranean, zone and tisanoreica diet on some health risk factors. Agro Food Ind Hi-Tech 21, 24-29.

43. Paoli A, Cenci L \& Grimaldi KA (2011) Effect of Ketogenic Mediterranean diet with phytoextracts and low carbohydrates/high-protein meals on weight, cardiovascular risk factors, body composition and diet compliance in Italian council employees. Nutr J 10, 112.

44. Paoli A, Mancin L, Giacona MC, et al. (2020) Effects of a ketogenic diet in overweight women with polycystic ovary syndrome. J Transl Med 18, 104.

45. Paoli A, Moro T, Bosco G, et al. (2015) Effects of $n$-3 polyunsaturated fatty acids ( $n-3)$ supplementation on some cardiovascular risk factors with a ketogenic Mediterranean diet. Mar Drugs 13, 996-1009.

46. McDonald L (1998) The Ketogenic Diet: a Complete Guide for the Dieter and Practitioner. Lyle McDonald.

47. Noakes T, Proudfoot J, Creed SA, et al. (2013) The Real Meal Revolution, 2nd ed. London: Constable \& Robinson Ltd.

48. Wylie-Rosett J, Aebersold K, Conlon B, et al. (2013) Health effects of low-carbohydrate diets: where should new research go? Curr Diabetes Rep 13, 271-278.

49. Hussain TA, Mathew TC, Dashti AA, et al. (2012) Effect of lowcalorie $v$. low-carbohydrate ketogenic diet in type 2 diabetes. Nutrition 28, 1016-1021.

50. Noakes TD \& Windt J (2017) Evidence that supports the prescription of low-carbohydrate high-fat diets: a narrative review. Br J Sports Med 51, 133-139.

51. Stafstrom CE \& Rho JM (2004) Epilepsy and the Ketogenic Diet. Springer Science \& Business Media.

52. Lodi A, Zarantonello L, Bisiacchi PS, et al. (2020) Ketonemia and glycemia affect appetite levels and executive functions in overweight females during two ketogenic diets. Obesity $\mathbf{2 8}$, 1868-1877.

53. Lodi A, Karsten B, Bosco G, et al. (2016) The effects of different high-protein low-carbohydrates proprietary foods on blood sugar in healthy subjects. J Med Food 19, 1085-1095.

54. Nelson DL, Lehninger AL \& Cox MM (2008) Lehninger Principles of Biochemistry. Macmillan.

55. Owen OE, Kalhan SC \& Hanson RW (2002) The key role of anaplerosis and cataplerosis for citric acid cycle function. $J$ Biol Chem 277, 30409-30412. 
56. Dhillon KK \& Gupta S (2019) Biochemistry, Ketogenesis StatPearls.

57. Herdt TH (2000) Ruminant adaptation to negative energy balance: influences on the etiology of ketosis and fatty liver. Vet Clin Food Anim Pract 16, 215-230.

58. Puchalska P \& Crawford PA (2017) Multi-dimensional roles of ketone bodies in fuel metabolism, signaling, and therapeutics. Cell Metab 25, 262-284.

59. Rui L (2011) Energy metabolism in the liver. Compr Physiol 4, $177-197$

60. Fedorovich SV, Voronina PP \& Waseem TV (2018) Ketogenic diet $v$. ketoacidosis: what determines the influence of ketone bodies on neurons? Neural Regen Res 13, 2060.

61. Laffel L (1999) Ketone bodies: a review of physiology, pathophysiology and application of monitoring to diabetes. Diabetes/Metab Res Rev 15, 412-426.

62. Dhillon KK \& Gupta S (2020) Biochemistry, Ketogenesis StatPearls.

63. Cantrell CB \& Mohiuddin SSJS (2020) Biochemistry, Ketone Metabolism. StatPearls.

64. Grabacka M, Pierzchalska M, Dean M, et al. (2016) Regulation of ketone body metabolism and the role of PPAR $\alpha$. Int J Mol Sci 17, 2093.

65. Leino R, Gerhart DZ, Duelli R, et al. (2001) Diet-induced ketosis increases monocarboxylate transporter (MCT1) levels in rat brain. Neurochem Int 38, 519-527.

66. Nehlig A (2004) Brain uptake and metabolism of ketone bodies in animal models. Prostaglandins Leukot Essent Fatty Acid 70, 265-275.

67. Neal EG, Chaffe H, Schwartz RH, et al. (2008) The ketogenic diet for the treatment of childhood epilepsy: a randomised controlled trial. Lancet Neurol 7, 500-506.

68. Levy RG, Cooper PN, Giri P, et al. (2012) Ketogenic diet and other dietary treatments for epilepsy.

69. Masino SA \& Rho JM (2012) Mechanisms of Ketogenic Diet Action. Jasper's Basic Mechanisms of the Epilepsies. 4th ed. National Center for Biotechnology Information.

70. Saponaro C, Gaggini M, Carli F, et al. (2015) The subtle balance between lipolysis and lipogenesis: a critical point in metabolic homeostasis. Nutrients 7, 9453-9474.

71. Ebbeling CB, Feldman HA, Klein GL, et al. (2018) Effects of a low carbohydrate diet on energy expenditure during weight loss maintenance: randomized trial. BMJ 363, k4583

72. Westman EC, Feinman RD, Mavropoulos JC, et al. (2007) Lowcarbohydrate nutrition and metabolism. Am J Clin Nutr 86 276-284.

73. Inoue $\mathrm{N}$, Matsunaga $\mathrm{Y}$, Satoh $\mathrm{H}$, et al. (2007) Enhanced energy expenditure and fat oxidation in humans with high BMI scores by the ingestion of novel and non-pungent capsaicin analogues (capsinoids). Biosci Biotechnol Biochem 71, 380-389.

74. Schultz L (1971) Management and nutritional aspects of ketosis. J Dairy Sci 54, 962-973.

75. Cox PJ, Kirk T, Ashmore T, et al. (2016) Nutritional ketosis alters fuel preference and thereby endurance performance in athletes. Cell Metab 24, 256-268.

76. Gershuni VM, Yan SL \& Medici V (2018) Nutritional ketosis for weight management and reversal of metabolic syndrome. Curr Nutr Rep 7, 97-106.

77. Bough KJ, Wetherington J, Hassel B, et al. (2006) Mitochondrial biogenesis in the anticonvulsant mechanism of the ketogenic diet. Ann Neurol 60, 223-235.

78. Ahola-Erkkila S, Carroll CJ, Peltola-Mjosund K, et al. (2010) Ketogenic diet slows down mitochondrial myopathy progression in mice. Hum Mol Genet 19, 1974-1984.
79. Bough KJ, Wetherington J, Hassel B, et al. (2006) Mitochondrial biogenesis in the anticonvulsant mechanism of the ketogenic diet. Ann Neurol 60, 223-235.

80. Ahola-Erkkilä S, Carroll CJ, Peltola-Mjösund K, et al. (2010) Ketogenic diet slows down mitochondrial myopathy progression in mice. Hum Mol Gen 19, 1974-1984.

81. Newman JC \& Verdin E (2017) $\beta$-Hydroxybutyrate: a signaling metabolite. Annu Rev Nutr 37, 51-76.

82. Wheless JW (2001) The ketogenic diet: an effective medical therapy with side effects. J child Neurol 16, 633-635.

83. Muscogiuri G, Barrea L, Laudisio D, et al. (2019) The management of very low-calorie ketogenic diet in obesity outpatient clinic: a practical guide. J Transl Med 17, 356.

84. Cohen CW, Fontaine KR, Arend RC, et al. (2019) A ketogenic diet is acceptable in women with ovarian and endometrial cancer and has no adverse effects on blood lipids: a randomized, controlled trial. Nutr Cancer 1-11.

85. Joshi S, Ostfeld RJ \& McMacken M (2019) The ketogenic diet for obesity and diabetes - enthusiasm outpaces evidence the ketogenic diet for obesity and diabetes: the ketogenic diet for obesity and diabetes. JAMA Internal Med 179, 1163-1164.

86. Stern L, Iqbal N, Seshadri P, et al. (2004) The effects of lowcarbohydrate $v$. conventional weight loss diets in severely obese adults: one-year follow-up of a randomized trial. Ann Intern Med 140, 778-785.

87. Gardner CD, Kiazand A, Alhassan S, et al. (2007) Comparison of the Atkins, Zone, Ornish, and LEARN diets for change in weight and related risk factors among overweight premenopausal women: the A to Z Weight Loss Study: a randomized trial. JAMA 297, 969-977.

88. Shai I, Schwarzfuchs D, Henkin Y, et al. (2008) Weight loss with a low-carbohydrate, Mediterranean, or low-fat diet. New Engl J Med 359, 229-241.

89. Foster GD, Wyatt HR, Hill JO, et al. (2003) A randomized trial of a low-carbohydrate diet for obesity. New Engl J Med $\mathbf{3 4 8}$, 2082-2090.

90. Cornier MA, Donahoo WT, Pereira R, et al. (2005) Insulin sensitivity determines the effectiveness of dietary macronutrient composition on weight loss in obese women. Obes Res 13, 703-709.

91. Ebbeling CB, Leidig MM, Feldman HA, et al. (2007) Effects of a low-glycemic load $v$. low-fat diet in obese young adults: a randomized trial. JAMA 297, 2092-2102.

92. McClain AD, Otten JJ, Hekler EB, et al. (2013) Adherence to a low-fat $\mathrm{v}$. low-carbohydrate diet differs insulin resistance status. Diabetes Obes Metab 15, 87-90.

93. McLaughlin T, Carter S, Lamendola C, et al. (2006) Effects of moderate variations in macronutrient composition on weight loss and reduction in cardiovascular disease risk in obese, insulin-resistant adults. Am J Clin Nutr 84, 813-821.

94. Pittas AG, Das SK, Hajduk CL, et al. (2005) A low-glycemic load diet facilitates greater weight loss in overweight adults with high insulin secretion but not in overweight adults with low insulin secretion in the CALERIE Trial. Diabetes Care 28, 2939-2941.

95. Rock CL, Flatt SW, Pakiz B, et al. (2016) Effects of diet composition on weight loss, metabolic factors and biomarkers in a 1-year weight loss intervention in obese women examined by baseline insulin resistance status. Metabolism 65, 1605-1613.

96. Gardner CD, Trepanowski JF, Del Gobbo LC, et al. (2018) Effect of low-fat $v$. low-carbohydrate diet on 12-month weight loss in overweight adults and the association with genotype pattern or insulin secretion: the DIETFITS randomized clinical trial. JAMA 319, 667-679. 
97. Gardner CD, Offringa LC, Hartle JC, et al. (2016) Weight loss on low-fat $v$. low-carbohydrate diets insulin resistance na among overweight adults adults obes: a randomized pilot trial. Obesity 24, 79-86.

98. Qi Q, Bray GA, Hu FB, et al. (2012) Weight-loss diets modify glucose-dependent insulinotropic polypeptide receptor rs2287019 genotype effects on changes in body weight, fasting glucose, and insulin resistance: the Preventing Overweight Using Novel Dietary Strategies trial. Am J Clin Nutr 95, 506-513.

99. Dopler Nelson M, Prabakar P, Kondragunta V, et al. (2010) Genetic phenotypes predict weight loss success: The right diet does matter. 50th Cardiovasc Dis Epidemiol Prev Nutr, Phys Activity Metab 79-80.

100. Stanton MV, Robinson JL, Kirkpatrick SM, et al. (2017) DIETFITS study (diet intervention examining the factors interacting with treatment success)-Study design and methods. Contemp Clin Trial 53, 151-161.

101. Howe HR, Heidal K, Choi MD, et al. (2011) Increased adipose tissue lipolysis after a 2-week high-fat diet in sedentary overweight/obese men. Metabolism 60, 976-981.

102. Swaminathan R, King R, Holmfield J, et al. (1985) Thermic effect of feeding carbohydrate, fat, protein and mixed meal in lean and obese subjects. Am J Clin Nutr 42, 177-181.

103. Jeukendrup A, Gleeson M (2018) Sport Nutrition. Human Kinetics.

104. Flatt J, Ravussin E, Acheson KJ, et al. (1985) Effects of dietary fat on postprandial substrate oxidation and on carbohydrate and fat balances. J Clin Investig 76, 1019-1024.

105. Czech MP (2017) Insulin action and resistance in obesity and type 2 diabetes. Nat Med 23, 804.

106. Samuel VT \& Shulman GIJC (2012) Mechanisms for insulin resistance: common threads and missing links. Cell 148, 852-871.

107. Hu S, Wang L, Togo J, et al. (2020) The carbohydrate-insulin model does not explain the impact of varying dietary macronutrients on the body weight and adiposity of mice. Mol Metab 32, 27-43.

108. Ashtary-Larky D, Bagheri R, Asbaghi O, et al. (2021) Effects of resistance training combined with a ketogenic diet on body cfomposition: a systematic review and meta-analysis. Crit Rev Food Sci Nutr 1-16.

109. Brehm BJ, Seeley RJ, Daniels SR, et al. (2003) A randomized trial comparing a very low carbohydrate diet and a calorierestricted low fat diet on body weight and cardiovascular risk factors in healthy women. $J$ Clin Endocrinol Metab 88, $1617-1623$

110. Gaspari A Scientific Review of Ketogenic Diet.

111. Dansinger ML, Gleason JA, Griffith JL, et al. (2005) Comparison of the Atkins, Ornish, Weight Watchers, and Zone diets for weight loss and heart disease risk reduction: a randomized trial. JAMA 293, 43-53.

112. Brinkworth GD, Noakes M, Buckley JD, et al. (2009) Longterm effects of a very-low-carbohydrate weight loss diet compared with an isocaloric low-fat diet after 12 months. Am JClin Nutr 90, 23-32.

113. Barkeling B, Rössner S \& Björvell H (1990) Effects of a highprotein meal (meat) and a high-carbohydrate meal (vegetarian) on satiety measured by automated computerized monitoring of subsequent food intake, motivation to eat and food preferences. Int J Obes 14, 743-751.

114. Stubbs R, Johnstone A \& Harbron C (1996) Breakfasts high in protein, fat or carbohydrate: effect on within-day appetite and energy balance. Eur J Clin Nutr 50, 409-417.

115. Astrup A (2005) The Satiating Power of Protein - a Key to Obesity Prevention? Oxford University Press.
116. Westerterp-Plantenga M, Rolland V, Wilson S, et al. (1999) Satiety related to $24 \mathrm{~h}$ diet-induced thermogenesis during high protein/carbohydrate $v$. high fat diets measured in a respiration chamber. Eur J Clin Nutr 53, 495.

117. Johnstone AM, Horgan GW, Murison SD, et al. (2008) Effects of a high-protein ketogenic diet on hunger, appetite, and weight loss in obese men feeding ad libitum. Am J Clin Nutr 87, 44-55.

118. Weigle DS, Breen PA, Matthys CC, et al. (2005) A high-protein diet induces sustained reductions in appetite, ad libitum caloric intake, and body weight despite compensatory changes in diurnal plasma leptin and ghrelin concentrations. Am J Clin Nutr 82, 41-48.

119. Sumithran P, Prendergast LA, Delbridge E, et al. (2013) Ketosis and appetite-mediating nutrients and hormones after weight loss. Eur J Clin Nutr 67, 759 .

120. Deemer SE, Plaisance EP \& Martins CJNR (2020) Impact of ketosis on appetite regulation - a review. Nutr Res 77, 1-11.

121. Holt SH \& Miller JB (1995) Increased insulin responses to ingested foods are associated with lessened satiety. Appetite 24, 43-54.

122. Miller S \& Petocz P (1996) Interrelationships among postprandial satiety, glucose and insulin responses and changes in subsequent food intake. Eur J Clin Nutr 50, 788-797.

123. Rodin JJHP (1985) Insulin levels, hunger, and food intake: an example of feedback loops in body weight regulation. Health Psychol 4, 1 .

124. Boden G, Sargrad K, Homko C, et al. (2005) Effect of a lowcarbohydrate diet on appetite, blood glucose levels, and insulin resistance in obese patients with type 2 diabetes. Ann Intern Med 142, 403-411.

125. Westman EC \& Volek JS (2002) Very-low-carbohydrate weight-loss diets revisited. Clevel Clinic J Med 69, 849

126. Badman MK, Pissios P, Kennedy AR, et al. (2007) Hepatic fibroblast growth factor 21 is regulated by PPAR $\alpha$ and is a key mediator of hepatic lipid metabolism in ketotic states. Cell Metab 5, 426-437.

127. Kliewer SA \& Mangelsdorf DJ (2009) Fibroblast growth factor 21: from pharmacology to physiology. Am J Clin Nutr $\mathbf{9 1}$, 254S-257S.

128. Nair KS, Halliday D \& Garrow J (1983) Thermic response to isoenergetic protein, carbohydrate or fat meals in lean and obese subjects. Clin Sci 65, 307-312.

129. Stubbs J, Ferres S \& Horgan G (2000) Energy density of foods: effects on energy intake. Crit Rev Food Sci Nutr 40, 481-515.

130. Yancy WS, Olsen MK, Guyton JR, et al. (2004) A low-carbohydrate, ketogenic diet $v$. a low-fat diet to treat obesity and hyperlipidemia: a randomized, controlled trial. Ann Intern Med 140, 769-777.

131. Gibson AA, Seimon RV, Lee CM, et al. (2015) Do ketogenic diets really suppress appetite? A systematic review and meta-analysis. Obes Rev 16, 64-76.

132. Johnstone AM, Horgan GW, Murison SD, et al. (2008) Effects of a high-protein ketogenic diet on hunger, appetite, and weight loss in obese men feeding ad libitum. Am J Clin Nutr 87, 44-55.

133. Rosen JC, Gross J, Loew D, et al. (1985) Mood and appetite during minimal-carbohydrate and carbohydrate-supplemented hypocaloric diets. Am J Clin Nutr 42, 371-379.

134. Bogardus C, LaGrange BM, Horton ES, et al. (1981) Comparison of carbohydrate-containing and carbohydraterestricted hypocaloric diets in the treatment of obesity. Endurance and metabolic fuel homeostasis during strenuous exercise. J Clin Investig 68, 399-404.

135. Crovetti R, Porrini M, Santangelo A, et al. (1998) The influence of thermic effect of food on satiety. J Sports Sci 52, 482-488. 
136. Dauncey M \& Bingham SA (1983) Dependence of 24 h energy expenditure in man on the composition of the nutrient intake. Br J Nutr 50, 1-13.

137. Veldhorst MA, Westerterp-Plantenga MS \& Westerterp KR (2009) Gluconeogenesis and energy expenditure after a high-protein, carbohydrate-free diet. Am J Clin Nutr 90, 519-526.

138. Westerterp KR (2004) Diet induced thermogenesis. Nutr Metab 1, 5 .

139. Acheson $K$ (1993) Influence of autonomic nervous system on nutrient-induced thermogenesis in humans. Nutrition $\mathbf{9}, 373$.

140. Feinman RD \& Fine EJ (2007) Nonequilibrium thermodynamics and energy efficiency in weight loss diets. Theor Biol Med Modell 4, 27

141. Fine EJ \& Feinman RD (2004) Thermodynamics of weight loss diets. Nutr Metab 1, 15

142. Halton TL \& Hu FB (2004) The effects of high protein diets on thermogenesis, satiety and weight loss: a critical review. $J \mathrm{Am}$ Coll Nutr 23, 373-385.

143. Jagadish S, Payne ET, Wong-Kisiel L, et al. (2019) The ketogenic and modified atkins diet therapy for children with refractory epilepsy of genetic etiology. Pediatr Neurol 94, 32-37.

144. Westerterp-Plantenga M, Nieuwenhuizen A, Tome D, et al. (2009) Dietary protein, weight loss, and weight maintenance. Annu Rev Nutr 29, 21-41.

145. Paoli A, Grimaldi K, Bianco A, et al. (2012) Medium term effects of a ketogenic diet and a Mediterranean diet on resting energy expenditure and respiratory ratio. BMC Proc $\mathbf{6}$, P37.

146. Hall KD, Chen KY, Guo J, et al. (2016) Energy expenditure and body composition changes after an isocaloric ketogenic diet in overweight and obese men. Am J Clin Nutr 104, 324-333.

147. Hall KD, Bemis T, Brychta R, et al. (2015) Calorie for calorie, dietary fat restriction results in more body fat loss than carbohydrate restriction in people with obesity. Cell Metab $\mathbf{2 2}$ 427-436.

148. Paoli A, Tinsley G, Bianco A, et al. (2019) The influence of meal frequency and timing on health in humans: the role of fasting. Nutrients 11, 719

149. Vidali S, Aminzadeh S, Lambert B, et al. (2015) Mitochondria: the ketogenic diet - a metabolism-based therapy. Int $J$ Biochem Cell Biol 63, 55-59.

150. Paoli A, Cenci L, Fancelli M, et al. (2010) Ketogenic diet and phytoextracts. Sci Advisory Board 21, 24.

151. Tagliabue A, Bertoli S, Trentani C, et al. (2012) Effects of the ketogenic diet on nutritional status, resting energy expenditure, and substrate oxidation in patients with medically refractory epilepsy: a 6-month prospective observational study. Clin Nutr 31, 246-249.

152. Volek JS \& Sharman MJ (2004) Cardiovascular and hormonal aspects of very-low-carbohydrate ketogenic diets. Obes Res 12, 115S-123S.

153. Samaha FF, Iqbal N, Seshadri P, et al. (2003) A low-carbohydrate as compared with a low-fat diet in severe obesity. NEngl J Med 348, 2074-2081.

154. Bazzano LA, Hu T, Reynolds K, et al. (2014) Effects of lowcarbohydrate and low-fat diets: a randomized trial. Ann Intern Med 161, 309-318.

155. Cardillo S, Seshadri P \& Iqbal N (2006) The effects of a lowcarbohydrate $v$. low-fat diet on adipocytokines in severely obese adults: three-year follow-up of a randomized trial Eur Rev Med Pharmacol Sci 10, 99.

156. Tobias DK, Chen M, Manson JE, et al. (2015) Effect of low-fat diet interventions $v$. other diet interventions on long-term weight change in adults: a systematic review and meta-analysis. Lancet Diabetes Endocrinol 3, 968-979.
157. Krieger JW, Sitren HS, Daniels MJ, et al. (2006) Effects of variation in protein and carbohydrate intake on body mass and composition during energy restriction: a meta-regression. Am J Clin Nutr 83, 260-274.

158. McPherson PAC \& McEneny J (2012) The biochemistry of ketogenesis and its role in weight management, neurological disease and oxidative stress. J Physiol Biochem 68, 141-151.

159. Fernández-Elías VE, Ortega JF, Nelson RK, et al. (2015) Relationship between muscle water and glycogen recovery after prolonged exercise in the heat in humans. Eur J Appl Physiol 115, 1919-1926.

160. Shiose K, Yamada Y, Motonaga K, et al. (2016) Segmental extracellular and intracellular water distribution and muscle glycogen after 72 -h carbohydrate loading using spectroscopic techniques. J Appl Physiol 121, 205-211.

161. Olsson KE \& Saltin BJAPS (1970) Variation in total body water with muscle glycogen changes in man. Physiol Scand 80, $11-18$

162. Rabast U, Vornberger K, Ehl M, et al. (1981) Loss of weight, sodium and water in obese persons consuming a high-or low-carbohydrate diet. Ann Nutr Metab 25, 341-349.

163. Rabast U, Kasper H, Schönborn JJN, et al. (1978) Comparative studies in obese subjects fed carbohydrate-restricted and high carbohydrate 1000-calorie formula diets. Nutr Metab 269-277.

164. Yang M-U \& Van Itallie TB (1976) Composition of weight lost during short-term weight reduction. Metabolic responses of obese subjects to starvation and low-calorie ketogenic and nonketogenic diets. J Clin Investig 58, 722-730.

165. Howell S \& Kones R (2017) 'Calories in, calories out' and macronutrient intake: the hope, hype, and science of calories. Am J Physiol Endocrinol Metab 313, E608-E612.

166. Aragon AA, Schoenfeld BJ, Wildman R, et al. (2017) International society of sports nutrition position stand: diets and body composition. J Int Soc Sport Nutr 14, 1-19.

167. Volek JS, Sharman MJ, Gómez AL, et al. (2004) Comparison of energy-restricted very low-carbohydrate and low-fat diets on weight loss and body composition in overweight men and women. Nutr Metab 1, 13

168. Arner P (2005) Human fat cell lipolysis: biochemistry, regulation and clinical role. Best Pract Res Clin Endocrinol Metab 19, 471-482.

169. Girard J, Duee P, Ferre P, et al. (1985) Fatty acid oxidation and ketogenesis during development. Reprod Nutr Dév 25, 303319.

170. McGarry JD \& Foster DW (1976) Ketogenesis and its Regulation. Elsevier.

171. Morigny P, Houssier M, Mouisel E, et al. (2016) Adipocyte lipolysis and insulin resistance. Biochimie 125, 259-266.

172. Courchesne-Loyer A, Croteau E, Castellano C-A, et al. (2017) Inverse relationship between brain glucose and ketone metabolism in adults during short-term moderate dietary ketosis: a dual tracer quantitative positron emission tomography study. I Cerebr Blood Flow Metab 37, 2485-2493.

173. Takeyama N, Itoh Y, Kitazawa Y, et al. (1990) Altered hepatic mitochondrial fatty acid oxidation and ketogenesis in endotoxic rats. Am J Physiol-Endocrinol Metab 259, E498-E505.

174. Kong Z, Sun S, Shi Q, et al. (2020) Short-Term ketogenic diet improves abdominal obesity in overweight/obese Chinese young females. Front Physiol 11, 856.

175. Gu Y, Yu H, Li Y, et al. (2013) Beneficial effects of an 8-week, very low carbohydrate diet intervention on obese subjects. Evid base Compl Alternative Med 2013, 760804

176. Bueno NB, de Melo ISV, de Oliveira SL, et al. (2013) Very-lowcarbohydrate ketogenic diet v. low-fat diet for na weight loss: a meta-analysis of randomised controlled trials. Br J Nutr $\mathbf{1 1 0}$, $1178-1187$. 
177. Castellana M, Conte E, Cignarelli A, et al. (2020) Efficacy and safety of very low calorie ketogenic diet (VLCKD) in patients with overweight and obesity: a systematic review and metaanalysis. Rev Endocr Metab Disord 21, 5-16.

178. Foster GD, Wyatt HR, Hill JO, et al. (2010) Weight and metabolic outcomes after 2 years on a low-carbohydrate $v$. low-fat diet: a randomized trial. Ann Intern Med 153, 147-157.

179. Moreno B, Crujeiras AB, Bellido D, et al. (2016) Obesity treatment by very low-calorie-ketogenic diet at two years: reduction in visceral fat and on the burden of disease. Endocrine $\mathbf{5 4}$, 681-690.

180. Moreno B, Bellido D, Sajoux I, et al. (2014) Comparison of a very low-calorie-ketogenic diet with a standard low-calorie diet in the treatment of obesity. Endocrine $\mathbf{4 7}, 793-805$

181. Truby H, Baic S, Delooy A, et al. (2006) Randomised controlled trial of four commercial weight loss programmes in the UK: initial findings from the BBC 'diet trials'. BMJ 332, 1309-1314.

182. Iqbal N, Vetter ML, Moore RH, et al. (2010) Effects of a lowintensity intervention that prescribed a low-carbohydrate vs. a low-fat diet in obese, diabetic participants. Obesity 18 , 1733-1738.

183. Davis NJ, Tomuta N, Schechter C, et al. (2009) Comparative study of the effects of a 1-year dietary intervention of a lowcarbohydrate diet $v$. a low-fat diet on weight and glycemic control in type 2 diabetes. Diabetes Care 32, 1147-1152.

184. Dansinger ML, Gleason JA, Griffith JL, et al. (2005) Comparison of the Atkins, Ornish, Weight Watchers, and Zone diets for weight loss and heart disease risk reduction: a randomized trial. JAMA 293, 43-53.

185. McAuley K, Smith K, Taylor R, et al. (2006) Long-term effects of popular dietary approaches on weight loss and features of insulin resistance. Int J Obes 30, 342-349.

186. Brinkworth GD, Wycherley TP, Noakes M, et al. (2016) Longterm effects of a very-low-carbohydrate weight-loss diet and an isocaloric low-fat diet on bone health in obese adults. Nutrition 32, 1033-1036.

187. Manninen AH (2004) Metabolic effects of the very-low-carbohydrate diets: misunderstood" villains" of human metabolism. J Soc Sport Nutr 1, 1-5.

188. Thomsen HH, Rittig N, Johannsen M, et al. (2018) Effects of 3hydroxybutyrate and free fatty acids on muscle protein kinetics and signaling during LPS-induced inflammation in humans: anticatabolic impact of ketone bodies. Am J Clin Nutr 108, 857-867.

189. Benlloch M, López-Rodríguez MM, Cuerda-Ballester M, et al. (2019) Satiating effect of a ketogenic diet and its impact on muscle improvement and oxidation state in multiple sclerosis patients. Nutrients 11, 1156.

190. Koutnik AP, D'Agostino DP, Egan B, et al. (2019) Anticatabolic effects of ketone bodies in skeletal muscle. Trends Endocrinol Metab 30, 227-229.

191. Cox PJ, Kirk T, Ashmore T, et al. (2016) Nutritional ketosis alters fuel preference and thereby endurance performance in athletes. Cell Metab 24, 256-268.

192. Sato K, Kashiwaya Y, Keon C, et al. (1995) Insulin, ketone bodies, and mitochondrial energy transduction. FASEB J 9 651-658.

193. Parker BA, Walton CM, Carr ST, et al. (2018) $\beta$ Hydroxybutyrate elicits favorable mitochondrial changes in skeletal muscle. Int J Mol Sci 19, 2247.

194. Huang Z, Huang L, Waters MJ, et al. (2020) Insulin and growth hormone balance: implications for obesity.

195. Moller N, Vendelbo MH, Kampmann U, et al. (2009) Growth hormone and protein metabolism. Clin Nutr 28, 597-603.
196. Hayashi AA \& Proud CG (2007) The rapid activation of protein synthesis by growth hormone requires signaling through mTOR. Am J Physiol-Endocrinol Metab 292, E1647-E1655.

197. Møller N, Copeland KC, Nair KSJE, et al. (2007) Growth hormone effects on protein metabolism. Endocrinol Metab Clin 36, 89-100.

198. Bielohuby M, Sawitzky M, Stoehr BJ, et al. (2011) Lack of dietary carbohydrates induces hepatic growth hormone (GH) resistance in rats. Endocrinology 152, 1948-1960.

199. Murata Y, Nishio K, Mochiyama T, et al. (2013) Fgf21 impairs adipocyte insulin sensitivity in mice fed a low-carbohydrate, high-fat ketogenic diet. Plos One 8, e69330.

200. Nakao R, Abe T, Yamamoto S, et al. (2019) Ketogenic diet induces skeletal muscle atrophy via reducing muscle protein synthesis and possibly activating proteolysis in mice. Sci Rep 9, 1-14.

201. Caton SJ, Bielohuby M, Bai Y, et al. (2012) Low-carbohydrate high-fat diets in combination with daily exercise in rats: effects on body weight regulation, body composition and exercise capacity. Physiol Behav 106, 185-192.

202. Widiatmaja DM, Prabowo GI \& Rejeki PS (2021) A Long-Term Ketogenic Diet Decreases Serum Insulin-Like Growth Factor-1 Levels in Mice. J Hunan Univ Nat Sci 48.

203. Urbain P, Strom L, Morawski L, et al. (2017) Impact of a 6-week non-energy-restricted ketogenic diet on physical fitness, body composition and biochemical parameters in healthy adults. Nutr Metab 14, 1-11.

204. Fraser D, Thoen J, Bondhus S, et al. (2000) Reduction in serum leptin and IGF-1 but preserved T-lymphocyte numbers and activation after a ketogenic diet in rheumatoid arthritis patients. Clin Exp Rheumatol 18, 209-214.

205. Manninen AH (2006) Very-low-carbohydrate diets and preservation of muscle mass. Nutr Metab 3, 1-4.

206. Masood W, Annamaraju P \& Uppaluri KR (2020) Ketogenic Diet. StatPearls. StatPearls Publishing.

207. Luger M, Holstein B, Schindler K, et al. (2013) Feasibility and efficacy of an isocaloric high-protein vs. standard diet on insulin requirement, body weight and metabolic parameters in patients with type 2 diabetes on insulin therapy. Exp Clin Endocrinol Diabetes 121, 286-294.

208. Kim JE, O'Connor LE, Sands LP, et al. (2016) Effects of dietary protein intake on body composition changes after weight loss in older adults: a systematic review and meta-analysis. Nutr Rev 74, 210-224.

209. Mettler S, Mitchell N \& Tipton KD (2010) Increased protein intake reduces lean body mass loss during weight loss in athletes. Med Sci Sports Exerc 42, 326-337.

210. Johnston CS, Sears B, Perry M, et al. (2017) Use of novel highprotein functional food products as part of a calorie-restricted diet to reduce insulin resistance and increase lean body mass in adults: a randomized controlled trial. Nutrients $\mathbf{9}, 1182$

211. Haghighat N, Ashtary-Larky D, Bagheri R, et al. (2020) The effect of 12 weeks of equicaloric high protein diet in regulating appetite and body composition of women with Normal Weight Obesity: a randomized controlled trial. Br J Nutr 1-20.

212. Pasiakos SM, Cao JJ, Margolis LM, et al. (2013) Effects of highprotein diets on fat-free mass and muscle protein synthesis following weight loss: a randomized controlled trial. FASEBJ 27, $3837-3847$.

213. Cuthbertson D, Smith K, Babraj J, et al. (2005) Anabolic signaling deficits underlie amino acid resistance of wasting, aging muscle. FASEB J 19, 1-22.

214. Fujita S, Dreyer HC, Drummond MJ, et al. (2007) Nutrient signalling in the regulation of human muscle protein synthesis. $J$ Physiol 582, 813-823. 
215. Noakes M, Foster PR, Keogh JB, et al. (2006) Comparison of isocaloric very low carbohydrate/high saturated fat and high carbohydrate/low saturated fat diets on body composition and cardiovascular risk. Nutr Metab 3, 7.

216. Brehm BJ, Spang SE, Lattin BL, et al. (2005) The role of energy expenditure in the differential weight loss in obese women on low-fat and low-carbohydrate diets. J Clin Endocrinol Metab 90, $1475-1482$.

217. Ashtary-Larky D, Daneghian S, Alipour M, et al. (2018) Waist circumference to height ratio: better correlation with fat mass than other anthropometric indices during dietary weight loss in different rates. Int J Endocrinol Metab 16.

218. Ashtary-Larky D, Ghanavati M, Lamuchi-Deli N, et al. (2017) Rapid weight loss vs. slow weight loss: which is more effective on body composition and metabolic risk factors? Int $J$ Endocrinol Metab 15

219. Vink RG, Roumans NJ, Arkenbosch LA, et al. (2016) The effect of rate of weight loss on long-term weight regain in adults with overweight and obesity. Obesity 24, 321-327.

220. Peos JJ, Norton LE, Helms ER, et al. (2019) Intermittent dieting: theoretical considerations for the athlete. Sports 7, 22.

221. Raymond JL \& Morrow K (2020) Krause and Mahan's Food and the Nutrition Care Process E-Book. Elsevier Health Sciences.

222. Gormsen LC, Svart M, Thomsen HH, et al. (2017) Ketone body infusion with 3-hydroxybutyrate reduces myocardial glucose uptake and increases blood flow in humans: a positron emission tomography study. I Am Heart Assoc $\mathbf{6}$, e005066

223. Ashtary Larky D, Bagheri R, Abbasnezhad A, et al. (2020) Effects of gradual weight loss $v$. rapid weight loss on body composition and resting metabolic rate: a systematic review and meta-analysis

224. Gomez-Arbelaez D, Crujeiras AB, Castro AI, et al. (2018) Resting metabolic rate of obese patients under very low calorie ketogenic diet. Nutr Metab 15, 18

225. McDaniel SS, Rensing NR, Thio LL, et al. (2011) The ketogenic diet inhibits the mammalian target of rapamycin (mTOR) pathway. Epilepsia 52, e7-e11.

226. Longo VD \& Mattson MP (2014) Fasting: molecular mechanisms and clinical applications. Cell Metab 19, 181-192.

227. Bolster DR, Crozier SJ, Kimball SR, et al. (2002) AMP-activated protein kinase suppresses protein synthesis in rat skeletal muscle through down-regulated mammalian target of rapamycin (mTOR) signaling. J Biol Chem 277, 23977-23980.

228. Cantó C, Gerhart-Hines Z, Feige JN, et al. (2009) AMPK regulates energy expenditure by modulating NAD+ metabolism and SIRT1 activity. Nature $\mathbf{4 5 8}, 1056$.

229. Garcia D \& Shaw RJ (2017) AMPK: mechanisms of Cellular Energy Sensing and Restoration of Metabolic Balance. $\mathrm{Mol}$ Cell 66, 789-800.

230. Jäger S, Handschin C, Pierre JS, et al. (2007) AMP-activated protein kinase (AMPK) action in skeletal muscle via direct phosphorylation of PGC- $1 \alpha$. Proc Natl Acad Sci 104, 1201712022.

231. Merrill GF, Kurth EJ, Hardie DG, et al. (1997) AICA riboside increases AMP-activated protein kinase, fatty acid oxidation, and glucose uptake in rat muscle. Am J Physiol 273, E1107-1112

232. Fulco M, Cen Y, Zhao P, et al. (2008) Glucose restriction inhibits skeletal myoblast differentiation by activating SIRT1 through AMPK-mediated regulation of Nampt. Dev Cell $\mathbf{1 4}$ 661-673.

233. Nemoto S, Fergusson MM \& Finkel T (2005) SIRT1 functionally interacts with the metabolic regulator and transcriptional coactivator PGC-1 $\alpha$. J Biol Chem 280, 16456-16460
234. Gerhart-Hines Z, Rodgers JT, Bare O, et al. (2007) Metabolic control of muscle mitochondrial function and fatty acid oxidation through SIRT1/PGC-1 $\alpha$. EMBO J 26, 1913-1923.

235. Rodgers JT, Lerin C, Haas W, et al. (2005) Nutrient control of glucose homeostasis through a complex of PGC- $1 \alpha$ and SIRT1. Nature 434, 113.

236. Lagouge M, Argmann C, Gerhart-Hines Z, et al. (2006) Resveratrol improves mitochondrial function and protects against metabolic disease by activating SIRT1 and PGC- $1 \alpha$. Cell 127, 1109-1122.

237. Anderson RM, Barger JL, Edwards MG, et al. (2008) Dynamic regulation of pgc- $1 \alpha$ localization and turnover implicates mitochondrial adaptation in calorie restriction and the stress response. Aging cell 7, 101-111.

238. Paoli A, Bianco A \& Grimaldi KA (2015) The ketogenic diet and sport: a possible marriage? Exerc Sport Sci Rev 43, 153162.

239. Draznin B, Wang C, Adochio R, et al. (2012) Effect of dietary macronutrient composition on AMPK and SIRT1 expression and activity in human skeletal muscle. Hormone Metab Res 44, 650-655.

240. Sandri M, Barberi L, Bijlsma A, et al. (2013) Signalling pathways regulating muscle mass in ageing skeletal muscle. The role of the IGF1-Akt-mTOR-FoxO pathway. Biogerontology 14, 303-323.

241. Verreijen AM, Verlaan S, Engberink MF, et al. (2014) A high whey protein-, leucine-, and vitamin D-enriched supplement preserves muscle mass during intentional weight loss in obese older adults: a double-blind randomized controlled trial. $A m J$ Clin Nutr 101, 279-286.

242. Weiss EP, Racette SB, Villareal DT, et al. (2007) Lower extremity muscle size and strength and aerobic capacity decrease with caloric restriction but not with exercise-induced weight loss. J Appl physiology 102, 634-640.

243. Stiegler P \& Cunliffe A (2006) The role of diet and exercise for the maintenance of fat-free mass and resting metabolic rate during weight loss. Sports Med 36, 239-262.

244. Fromentin C, Tomé D, Nau F, et al. (2013) Dietary proteins contribute little to glucose production, even under optimal gluconeogenic conditions in healthy humans. Diabetes $\mathbf{6 2}$, 1435-1442.

245. Pozefsky T, Tancredi RG, Moxley RT, et al. (1976) Effects of brief starvation on muscle amino acid metabolism in nonobese man. J Clin Investig 57, 444-449.

246. Benoit FL, Martin RL \& Watten RH (1965) Changes in body composition during weight reduction in obesity: balance studies comparing effects of fasting and a ketogenic diet. Ann Intern Med 63, 604-612.

247. Freeman J, Veggiotti P, Lanzi G, et al. (2006) The ketogenic diet: from molecular mechanisms to clinical effects. Epilepsy $\operatorname{Res}$ 68, 145-180.

248. Soeters MR, Soeters PB, Schooneman MG, et al. (2012) Adaptive reciprocity of lipid and glucose metabolism in human short-term starvation. Am J Physiol-Endocrinol Metab 303, E1397-E1407.

249. Young CM, Scanlan SS, Im HS, et al. (1971) Effect on body composition and other parameters in obese young men of carbohydrate level of reduction diet. Am J Clin Nutr 24, 290-296.

250. Manninen AH (2004) Is a calorie really a calorie? Metabolic advantage of low-carbohydrate diets. J Int Soc Sports Nutr 1, 21.

251. Manninen AH (2006) Very-low-carbohydrate diets and preservation of muscle mass. Nutr Metab 3, 9 .

252. Mathai JK, Liu Y \& Stein HH (2017) Values for digestible indispensable amino acid scores (DIAAS) for some dairy and plant proteins may better describe protein quality than values 
calculated using the concept for protein digestibility-corrected amino acid scores (PDCAAS). Br J Nutr 117, 490-499.

253. Paoli A, Grimaldi K, D'Agostino D, et al. (2012) Ketogenic diet does not affect strength performance in elite artistic gymnasts. J Int Soc Sports Nutr 9, 34.

254. Urbain P, Strom L, Morawski L, et al. (2017) Impact of a 6-week non-energy-restricted ketogenic diet on physical fitness, body composition and biochemical parameters in healthy adults. Nutr Metab 14, 17.

255. Churchward-Venne TA, Burd NA \& Phillips SM (2012) Nutritional regulation of muscle protein synthesis with resistance exercise: strategies to enhance anabolism. Nutr Metab 9, $1-8$.

256. Greenhaff PL, Karagounis L, Peirce N, et al. (2008) Disassociation between the effects of amino acids and insulin on signaling, ubiquitin ligases, and protein turnover in human muscle. Am J Physiol-Endocrinol Metab 295, E595-E604.

257. Roy B, Tarnopolsky M, MacDougall J, et al. (1997) Effect of glucose supplement timing on protein metabolism after resistance training. J Appl Physiol 82, 1882-1888.

258. Børsheim E, Cree MG, Tipton KD, et al. (2004) Effect of carbohydrate intake on net muscle protein synthesis during recovery from resistance exercise. J Appl Physiol 96, 674-678.

259. Gelfand RA \& Barrett EJ (1987) Effect of physiologic hyperinsulinemia on skeletal muscle protein synthesis and breakdown in man. J Clin Investig 80, 1-6.

260. Biolo G, Williams BD, Fleming R, et al. (1999) Insulin action on muscle protein kinetics and amino acid transport during recovery after resistance exercise. Diabetes 48, 949-957.

261. Wilkes EA, Selby AL, Atherton PJ, et al. (2009) Blunting of insulin inhibition of proteolysis in legs of older subjects may contribute to age-related sarcopenia. Am J Clin Nutr 90, $1343-1350$.

262. Abdulla H, Smith K, Atherton PJ, et al. (2016) Role of insulin in the regulation of human skeletal muscle protein synthesis and breakdown: a systematic review and meta-analysis, Diabetologia 59, 44-55.

263. Børsheim E, Tipton KD, Wolf SE, et al. (2002) Essential amino acids and muscle protein recovery from resistance exercise. Am J Physiol-Endocrinol Metab

264. Miller SL, Tipton KD, Chinkes DL, et al. (2003) Independent and combined effects of amino acids and glucose after resistance exercise. Med Sci Sports Exerc 35, 449-455.

265. Rasmussen BB, Tipton KD, Miller SL, et al. (2000) An oral essential amino acid-carbohydrate supplement enhances muscle protein anabolism after resistance exercise. $J$ Appl Physiol 88, 386-392.

266. Tipton KD, Ferrando AA, Phillips SM, et al. (1999) Postexercise net protein synthesis in human muscle from orally administered amino acids. Am J Physiol-Endocrinol Metab 276, E628-E634.

267. Tipton KD, Rasmussen BB, Miller SL, et al. (2001) Timing of amino acid-carbohydrate ingestion alters anabolic response of muscle to resistance exercise. Am J Physiol-Endocrinol Metab

268. Gomez-Arbelaez D, Bellido D, Castro AI, et al. (2017) Body composition changes after very-low-calorie ketogenic diet in obesity evaluated by 3 standardized methods. J Clin Endocrinol Metab 102, 488-498.

269. Going SB, Massett MP, Hall MC, et al. (1993) Detection of small changes in body composition by dual-energy x-ray absorptiometry. Am J Clin Nutr 57, 845-850.

270. Koulmann N, Jimenez C, Regal D, et al. (2000) Use of bioelectrical impedance analysis to estimate body fluid compartments after acute variations of the body hydration level. Med $S c i$ Sports Exerc 32, 857-864.
271. Guth E (2014) Healthy weight loss. JAMA 312, 974-974.

272. Denke MA (2001) Metabolic effects of high-protein, lowcarbohydrate diets. Am J Cardiol 88, 59-61.

273. Williams R, Wood L, Collins C, et al. (2015) Effectiveness of weight loss interventions-is there a difference between men and women: a systematic review. Obes Rev 16, 171-186.

274. Kashubeck-West S, Mintz LB \& Weigold IJSR (2005) Separating the effects of gender and weight-loss desire on body satisfaction and disordered eating behavior. Sex Roles $\mathbf{5 3}, 505-518$

275. Salvador AC, Arends D, Barrington WT, et al. (2021) Sex-specific genetic architecture in response to American and ketogenic diets. Int J Obes 1-14.

276. Sahagun E, Bachman BB, Kinzig KP, et al. (2021) Sex-specific effects of ketogenic diet after pre-exposure to a high-fat, highsugar diet in rats. Nutr Metab Cardiovasc Dis 31, 961-971.

277. Lyngstad A, Nymo S, Coutinho SR, et al. (2019) Investigating the effect of sex and ketosis on weight-loss-induced changes in appetite. Am J Clin Nutr 109, 1511-1518.

278. Brinkworth GD, Noakes M, Clifton PM, et al. (2009) Effects of a low carbohydrate weight loss diet on exercise capacity and tolerance in obese subjects. Obesity 17, 1916-1923.

279. Gerdts E \& Regitz-Zagrosek V (2019) Sex differences in cardiometabolic disorders. Nat Med 25, 1657-1666.

280. Moghadam B, Bagheri R, Ashtary-Larky D, et al. (2020) The effects of concurrent training order on satellite cell-related markers, body composition, muscular and cardiorespiratory fitness in older men with Sarcopenia. J Nutr Health Aging 24, 796-804.

281. Ashtary-Larky D, Vanani AN, Hosseini SA, et al. (2018) Relationship between the body fat percentage and anthropometric measurements in athletes compared with non-athletes. Zahedan J Res Med Sci 20, e10422.

282. Mohammadi HR, Khoshnam MS \& Khoshnam E (2018) Effects of different modes of exercise training on body composition and risk factors for cardiovascular disease in middle-aged men. Int J Prev Med 9, 9

283. Bagheri R, Moghadam BH, Church DD, et al. (2020) The effects of concurrent training order on body composition and serum concentrations of follistatin, myostatin and GDF11 in sarcopenic elderly men. Exp Gerontol 133, 110869.

284. Wong A, Figueroa A, Fischer SM, et al. (2020) The effects of mat pilates training on vascular function and body fatness in obese young women with elevated. Blood Pressure 33, 563-569.

285. You T, Disanzo BL, Wang X, et al. (2011) Adipose tissue endocannabinoid system gene expression: depot differences and effects of diet and exercise. Lipid Health Dis 10, 194.

286. Theodorakopoulos C, Jones J, Bannerman E, et al. (2017) Effectiveness of nutritional and exercise interventions to improve body composition and muscle strength or function in sarcopenic obese older adults: a systematic review. Nutr Res 43, 3-15.

287. Yamaguchi T, Saiki A, Endo K, et al. (2011) Effect of exercise performed at anaerobic threshold on serum growth hormone and body fat distribution in obese patients with type 2 diabetes. Obes Res Clin Pract 5, e9-e16.

288. Jakicic JM, Clark K, Coleman E, et al. (2001) Appropriate intervention strategies for weight loss and prevention of weight regain for adults. Med Sci Sports Exerc 33, 2145-2156.

289. Donnelly JE, Blair SN, Jakicic JM, et al. (2009) Appropriate physical activity intervention strategies for weight loss and prevention of weight regain for adults. Med Sci Sports Exerc 41, 459-471.

290. Chilibeck PD, Calder AW, Sale DG, et al. (1997) A comparison of strength and muscle mass increases during resistance 
training in young women. Eur I Appl Physiol Occup Physiol 77, 170-175

291. Candow DG \& Burke DG (2007) Effect of short-term equalvolume resistance training with different workout frequency on muscle mass and strength in untrained men and women. J Strength Cond Res 21, 204.

292. Antonio J, Ellerbroek A, Silver T, et al. (2015) A high protein diet $(3.4 \mathrm{~g} / \mathrm{kg} / \mathrm{d})$ combined with a heavy resistance training program improves body composition in healthy trained men and women-a follow-up investigation. I Int Soc Sports Nutr 12, 39.

293. Antonio J, Ellerbroek A, Silver T, et al. (2016) The effects of a high protein diet on indices of health and body composition-a crossover trial in resistance-trained men. J Int Soc Sports Nutr 13, 3 .

294. Wycherley TP, Noakes M, Clifton PM, et al. (2010) A high-protein diet with resistance exercise training improves weight loss and body composition in overweight and obese patients with type 2 diabetes. Diabetes Care 33, 969-976.

295. Kerksick CM, Wilborn CD, Roberts MD, et al. (2018) ISSN exercise \& sports nutrition review update: research \& recommendations. J Int Soc Sports Nutr 15, 38.

296. Burke LM, Hawley JA, Wong SH, et al. (2011) Carbohydrates for training and competition. I Sport Sci 29, S17-S27.

297. Burke LM, Loucks AB \& Broad N (2006) Energy and carbohydrate for training and recovery. J Sports Sci 24, 675-685.

298. Burke LM, Cox GR, Cummings NK, et al. (2001) Guidelines for daily carbohydrate intake. Sports Med 31, 267-299.

299. Jeukendrup AEJSM (2017) Periodized nutrition for athletes. Sports Med 47, 51-63.

300. Kerksick C, Harvey T, Stout J, et al. (2008) International Society of Sports Nutrition position stand: nutrient timing. $J$ Int Soc Sports Nutr 5, 1-12.

301. Fujita S, Glynn EL, Timmerman KL, et al. (2009) Supraphysiological hyperinsulinaemia is necessary to stimulate skeletal muscle protein anabolism in older adults: evidence of a true age-related insulin resistance of muscle protein metabolism. Diabetologia 52, 1889-1898.

302. Hillier TA, Fryburg DA, Jahn LA, et al. (1998) Extreme hyperinsulinemia unmasks insulin's effect to stimulate protein synthesis in the human forearm. Am J Physiol-Endocrinol Metab 274, E1067-E1074.

303. Nygren J \& Nair KSJD (2003) Differential regulation of protein dynamics in splanchnic and skeletal muscle beds by insulin and amino acids in healthy human subjects. Diabetes $\mathbf{5 2}$ 1377-1385.

304. Bird SP, Tarpenning KM \& Marino F (2006) Independent and combined effects of liquid carbohydrate/essential amino acid ingestion on hormonal and muscular adaptations following resistance training in untrained men. Eur J Appl Physiol 97, 225-238.

305. Kiens B \& Astrup AJE (2015) Ketogenic diets for fat loss and exercise performance: benefits and safety? Exerc Sport Sci Rev 43, 109

306. Zinn C, Wood M, Williden M, et al. (2017) Ketogenic diet benefits body composition and well-being but not performance in a pilot case study of New Zealand endurance athletes. J Int Soc Sports Nutr 14, 22

307. Sawyer JC, Wood RJ, Davidson PW, et al. (2013) Effects of a short-term carbohydrate-restricted diet on strength and power performance. J Strength Cond Res 27, 2255-2262.

308. Miller VJ, LaFountain RA, Barnhart E, et al. (2020) A Ketogenic diet combined with exercise alters mitochondrial function in human skeletal muscle while improving metabolic health. Am I Pbysiol Endocrinol Metab 319 , E995-E1007.
309. Durkalec-Michalski K, Nowaczyk PM \& Siedzik K (2019) Effect of a four-week ketogenic diet on exercise metabolism in CrossFit-trained athletes. J Int Soc Sports Nutr 16, 16.

310. LaFountain RA, Miller VJ, Barnhart EC, et al. (2019) Extended ketogenic diet and physical training intervention in military personnel. Military Med 184, e538-e547.

311. Vargas S, Romance R, Petro JL, et al. (2018) Efficacy of ketogenic diet on body composition during resistance training in trained men: a randomized controlled trial. I Int Soc Sports Nutr 15, 31

312. Jabekk PT, Moe IA, Meen HD, et al. (2010) Resistance training in overweight women on a ketogenic diet conserved lean body mass while reducing body fat. Nutr Metab 7, 17.

313. Gregory RM, Hamdan H, Torisky D, et al. (2017) A low-carbohydrate ketogenic diet combined with 6-weeks of crossfit training improves body composition and performance. Int J Sports Exerc Med 3, 1-10.

314. McSwiney FT, Wardrop B, Hyde PN, et al. (2018) Keto-adaptation enhances exercise performance and body composition responses to training in endurance athletes. Metabolism $\mathbf{8 1}$, 25-34.

315. Dostal T, Plews DJ, Hofmann P, et al. (2019) Effects of a 12week very-low carbohydrate high-fat diet on maximal aerobic capacity, high-intensity intermittent exercise, and cardiac autonomic regulation: non-randomized parallel-group study. Front Physiol 10, 912.

316. Robinson AM, Williamson DH (1980) Physiological roles of ketone bodies as substrates and signals in mammalian tissues. Physiol Rev 60, 143-187.

317. Newman JC, Verdin E (2014) Ketone bodies as signaling metabolites. Trends Endocrinol Metab 25, 42-52.

318. Newman JC, Verdin E (2014) $\beta$-hydroxybutyrate: much more than a metabolite. Diabetes Res Clin Pract 106, 173-181.

319. Koeslag J, Noakes T \& Sloan A (1980) Post-exercise ketosis. J Physiol 301, 79-90.

320. Balasse EO \& Féry F (1989) Ketone body production and disposal: effects of fasting, diabetes, and exercise. Diabetes/ Metab Rev 5, 247-270.

321. Johnson R, Walton J, Krebs H, et al. (1969) Metabolic fuels during and after severe exercise in athletes and non-athletes. Lancet 294, 452-455.

322. Fery F, Balasse E (1986) Response of ketone body metabolism to exercise during transition from postabsorptive to fasted state. Am J Physiology-Endocrinology Metab 250, E495-E501.

323. Johnson R, Walton J (1971) Fitness, fatness, and post-exercise ketosis. Lancet 297, 566-568.

324. Goedecke JH, Christie C, Wilson G, et al. (1999) Metabolic adaptations to a high-fat diet in endurance cyclists. Metabolism 48, 1509-1517.

325. Klement RJ, Frobel T, Albers T, et al. (2013) A pilot case study on the impact of a self-prescribed ketogenic diet on biochemical parameters and running performance in healthy and physically active individuals. Nutr Med 1 .

326. Mitchell WK, Wilkinson DJ, Phillips BE, et al. (2016) Human skeletal muscle protein metabolism responses to amino acid nutrition. Adv Nutr 7, 828S-838S.

327. Phillips SM (2011) The science of muscle hypertrophy: making dietary protein count. Eur J Sport Sci 70, 100-103.

328. Tipton KD \& Phillips SM (2013) Dietary Protein for Muscle Hypertrophy. Limits of Human Endurance. Karger Publishers.

329. van Loon LJ \& Gibala MJ (2011) Dietary Protein to Support Muscle Hypertrophy. Sports Nutrition: More Than Just Calories-Triggers for Adaptation. Karger Publishers.

330. Paoli A, Cancellara P, Pompei P, et al. (2019) Ketogenic diet and skeletal muscle hypertrophy: a frenemy relationship? J Hum Kinet 68, 233-247. 
331. McKay AK, Peeling P, Pyne DB, et al. (2019) Acute carbohydrate ingestion does not influence the post-exercise iron-regulatory response in elite keto-adapted race walkers. J Sci Med Sport 22, 635-640.

332. Ma S \& Suzuki KJS (2019) Keto-adaptation and endurance exercise capacity, fatigue recovery, and exercise-induced muscle and organ damage prevention: a narrative review. Sports 7, 40 .

333. Kennedy AR, Pissios P, Otu H, et al. (2007) A high-fat, ketogenic diet induces a unique metabolic state in mice. $\mathrm{Am} \mathrm{J}$ Physiol-Endocrinol Metab 292, E1724-E1739.

334. Frommelt L, Bielohuby M, Menhofer D, et al. (2014) Effects of low carbohydrate diets on energy and nitrogen balance and body composition in rats depend on dietary protein-to-energy ratio. Nutrition 30, 863-868.

335. Volek JS, Phinney SD, Forsythe CE, et al. (2009) Carbohydrate restriction has a more favorable impact on the metabolic syndrome than a low fat diet. Lipids $\mathbf{4 4}, 297-309$.

336. Volek JS, Sharman MJ, Love DM, et al. (2002) Body composition and hormonal responses to a carbohydrate-restricted diet. Metab Clin Exp 51, 864-870

337. Willi SM, Oexmann MJ, Wright NM, et al. (1998) The effects of a high-protein, low-fat, ketogenic diet on adolescents with morbid obesity: body composition, blood chemistries, and sleep abnormalities. Pediatrics 101, 61-67.

338. Kephart W, Pledge C, Roberson P, et al. (2018) The threemonth effects of a ketogenic diet on body composition, blood parameters, and performance metrics in CrossFit trainees: a pilot study. Sports $\mathbf{6}, 1$.

339. Wood RJ, Gregory SM, Sawyer J, et al. (2012) Preservation of fat-free mass after two distinct weight loss diets with and without progressive resistance exercise. Metab Syndrome Related Disord 10, 167-174.

340. Vargas-Molina S, Petro JL, Romance R, et al. (2020) Effects of a ketogenic diet on body composition and strength in trained women. J Int Soc Sports Nutr 17, 1-10.

341. Zajac A, Poprzecki S, Maszczyk A, et al. (2014) The effects of a ketogenic diet on exercise metabolism and physical performance in off-road cyclists. Nutrients 6, 2493-2508.

342. Coggan AR, Raguso CA, Gastaldelli A, et al. (2000) Fat metabolism during high-intensity exercise in endurance-trained and untrained men. Metabolism 49, 122-128.

343. Boyd A, Giamber S, Mager M, et al. (1974) Lactate inhibition of lipolysis in exercising man. Metabolism 23, 531-542.

344. Wilson JM, Lowery RP, Roberts MD, et al. (2017) The effects of ketogenic dieting on body composition, strength, power, and hormonal profiles in resistance training males. $J$ Strength Condit Res 34, 3463-3474.

345. Rhyu HS \& Cho SY (2014) The effect of weight loss by ketogenic diet on the body composition, performance-related physical fitness factors and cytokines of Taekwondo athletes. J Exerc Rehab 10, 326.

346. Paoli A, Cenci L, Pompei P, et al. (2021) Effects of two months of very low carbohydrate ketogenic diet on body composition, muscle strength, muscle area, and blood parameters in competitive natural body builders. Nutrients $\mathbf{1 3}, 374$.

347. Vidić V, Ilić V, Toskić L, et al. (2021) Effects of calorie restricted low carbohydrate high fat ketogenic vs. non-ketogenic diet on strength, body-composition, hormonal and lipid profile in trained middle-aged men. Clin Nutr 40, 1495-1502.

348. Despres J, Bouchard C, Savard R, et al. (1984) The effect of a 20-week endurance training program on adipose-tissue morphology and lipolysis in men and women. Metabolism 33, 235-239.

349. Kelley GA, Kelley KSJM (2006) Effects of aerobic exercise on C-reactive protein, body composition, and maximum oxygen consumption in adults: a meta-analysis of randomized controlled trials. Metabolism 55, 1500-1507.

350. Yeo WK, Carey AL, Burke L, et al. (2011) Fat adaptation in well-trained athletes: effects on cell metabolism. Appl Physiol Nutr Metab 36, 12-22.

351. Volek JS, Noakes T \& Phinney SD (2015) Rethinking fat as a fuel for endurance exercise. Eur J Sport Sci 15, 13-20.

352. Burke LM (2021) Ketogenic low-CHO, high-fat diet: the future of elite endurance sport? J Physiol 599, 819-843.

353. Burke LM, Ross ML, Garvican-Lewis LA, et al. (2017) Low carbohydrate, high fat diet impairs exercise economy and negates the performance benefit from intensified training in elite race walkers. J Physiol 595, 2785-2807.

354. Shaw DM, Merien F, Braakhuis A, et al. (2019) Effect of a Ketogenic Diet on Submaximal Exercise Capacity and Efficiency in Runners. Med Sci Sport Exerc 51, 2135-2146.

355. Burke LM, Whitfield J, Heikura IA, et al. (2021) Adaptation to a low carbohydrate high fat diet is rapid but impairs endurance exercise metabolism and performance despite enhanced glycogen availability. J Physiol 599, 771-790.

356. Yeo WK, Lessard SJ, Chen Z-P, et al. (2008) Fat adaptation followed by carbohydrate restoration increases AMPK activity in skeletal muscle from trained humans. J Appl Physiol 105, 1519-1526.

357. Stellingwerff T, Spriet LL, Watt MJ, et al. (2006) Decreased PDH activation and glycogenolysis during exercise following fat adaptation with carbohydrate restoration. Am J PhysiolEndocrinol Metab 290, E380-E388.

358. Cameron-Smith D, Burke LM, Angus DJ, et al. (2003) A shortterm, high-fat diet up-regulates lipid metabolism and gene expression in human skeletal muscle. Am J Clin Nutr 77, 313-318.

359. Goedecke JH, Christie C, Wilson G, et al. (1999) Metabolic adaptations to a high-fat diet in endurance cyclists. Metabolism 48, 1509-1517.

360. Yeo WK, Paton CD, Garnham AP, et al. (2008) Skeletal muscle adaptation and performance responses to once a day $v$. twice every second day endurance training regimens. J Appl Physiol 105, 1462-1470.

361. White AM, Johnston CS, Swan PD, et al. (2007) Blood ketones are directly related to fatigue and perceived effort during exercise in overweight adults adhering to low-carbohydrate diets for weight loss: a pilot study. JAm Dietetic Assoc 107, 1792-1796.

362. Phinney SD, Bistrian BR, Evans W, et al. (1983) The human metabolic response to chronic ketosis without caloric restriction: preservation of submaximal exercise capability with reduced carbohydrate oxidation. Metabolism 32, 769-776.

363. Volek JS, Freidenreich DJ, Saenz C, et al. (2016) Metabolic characteristics of keto-adapted ultra-endurance runners. Metabolism 65, 100-110.

364. McSwiney FT, Fusco B, McCabe L, et al. (2021) Changes in body composition and substrate utilization after a short-term ketogenic diet in endurance-trained males. Biol Sport 38, 145 .

365. Kang J, Ratamess NA, Faigenbaum AD, et al. (2020) Ergogenic properties of ketogenic diets in normal-weight individuals: a systematic review. J Am Coll Nutr 39, 665-675.

366. Ma S, Huang Q, Tominaga T, et al. (2018) An 8-week ketogenic diet alternated interleukin-6, ketolytic and lipolytic gene expression, and enhanced exercise capacity in mice. Nutrients 10, 1696.

367. Burke LM, Angus DJ, Cox GR, et al. (2000) Effect of fat adaptation and carbohydrate restoration on metabolism and performance during prolonged cycling. J Appl Physiol 89, 2413-2421. 
368. Burke LM, Hawley JA, Angus DJ, et al. (2002) Adaptations to short-term high-fat diet persist during exercise despite high carbohydrate availability. Med Sci Sports Exerc 34, 83-91.

369. Helge JW, Watt PW, Richter EA, et al. (2001) Fat utilization during exercise: adaptation to a fat-rich diet increases utilization of plasma fatty acids and very low density lipoprotein-triacylglycerol in humans. J Physiol 537, 1009-1020.

370. Lambert EV, Speechly DP, Dennis SC, et al. (1994) Enhanced endurance in trained cyclists during moderate intensity exercise following 2 weeks adaptation to a high fat diet. Eur J Appl Physiol Occup Physiol 69, 287-293.

371. Lambert EV, Hawley J, Goedecke J, et al. (1997) Nutritional strategies for promoting fat utilization and delaying the onset of fatigue during prolonged exercise. J Sports Sci 15, 315-324.

372. Webster CC, Noakes TD, Chacko SK, et al. (2016) Gluconeogenesis during endurance exercise in cyclists habituated to a long-term low carbohydrate high-fat diet. $J$ Physiol 594, 4389-4405.

373. Puglisi M (2019) Dietary Fat and Sports Performance. Nutrition and Enhanced Sports Performance. Elsevier.

374. Turcotte LP (1999) Role of fats in exercise: types and quality. Clin Sports Med 18, 485-498.

375. Schrauwen P, Wagenmakers A, van Marken Lichtenbelt WD, et al. (2000) Increase in fat oxidation on a high-fat diet is accompanied by an increase in triglyceride-derived fatty acid oxidation. Diabetes 49, 640-646.
376. Kiens B, Essen-Gustavsson B, Gad P, et al. (1987) Lipoprotein lipase activity and intramuscular triglyceride stores after long-term high-fat and high-carbohydrate diets in physically trained men. Clin Physiol 7, 1-9.

377. Coyle EF, Jeukendrup AE, Oseto MC, et al. (2001) Low-fat diet alters intramuscular substrates and reduces lipolysis and fat oxidation during exercise. Am J Physiol-Endocrinol Metab 280, E391-E398.

378. Starling RD, Trappe TA, Parcell AC, et al. (1997) Effects of diet on muscle triglyceride and endurance performance. $J \mathrm{Appl}$ Physiol 82, 1185-1189.

379. Michalczyk M, Zajac A, Mikolajec K, et al. (2018) No modification in blood lipoprotein concentration but changes in body composition after 4 weeks of low carbohydrate diet (LCD) followed by 7 days of carbohydrate loading in basketball players. J Hum Kinet 65, 125.

380. Hearris M, Hammond K, Fell J, et al. (2018) Regulation of muscle glycogen metabolism during exercise: implications for endurance performance and training adaptations. Nutrients 10, 298

381. Cipryan L, Plews DJ, Ferretti A, et al. (2018) Effects of a 4-week very low-carbohydrate diet on high-intensity interval training responses. J Sports Sci Med 17, 259.

382. Gyorkos A, Baker MH, Miutz LN, et al. (2019) Carbohydraterestricted diet and high-intensity interval training exercise improve cardio-metabolic and inflammatory profiles in metabolic syndrome: a randomized crossover trial. Cureus 11, e5596. 